\title{
WestVirginiaUniversity
}

THE RESEARCH REPOSITORY @ WVU

Graduate Theses, Dissertations, and Problem Reports

1998

\section{Acquisition of observing responses with delayed conditioned reinforcement}

Gregory A. Lieving

West Virginia University

Follow this and additional works at: https://researchrepository.wvu.edu/etd

\section{Recommended Citation}

Lieving, Gregory A., "Acquisition of observing responses with delayed conditioned reinforcement" (1998). Graduate Theses, Dissertations, and Problem Reports. 924.

https://researchrepository.wvu.edu/etd/924

This Thesis is protected by copyright and/or related rights. It has been brought to you by the The Research Repository @ WVU with permission from the rights-holder(s). You are free to use this Thesis in any way that is permitted by the copyright and related rights legislation that applies to your use. For other uses you must obtain permission from the rights-holder(s) directly, unless additional rights are indicated by a Creative Commons license in the record and/ or on the work itself. This Thesis has been accepted for inclusion in WVU Graduate Theses, Dissertations, and Problem Reports collection by an authorized administrator of The Research Repository @ WVU. For more information, please contact researchrepository@mail.wvu.edu. 


\section{Acquisition of Observing Responses}

With Delayed Conditioned Reinforcement

By

$$
\text { Gregory A. Lieving }
$$

A THESIS

$$
\text { Submitted to }
$$

The Eberly College of Arts and Sciences

$$
\text { at }
$$

West Virginia University

in partial fulfillment of the requirements for the degree of Master of Arts in Psychology

$$
\begin{aligned}
& \text { Department of Psychology } \\
& \text { Morgantown, West Virginia }
\end{aligned}
$$

$$
1998
$$

Committee Chair: Kennon A. Lattal, Ph.D. 


\section{Acknowledgments}

I would like to express my gratitude and appreciation to Kennon A. Lattal, for his ever-present support and guidance. Andy's encouragement has been (and continues to be) the essential feature of my professional development. The improvement of my behavior in the areas of writing, professionalism, integrity, scientific creativity, critical thinking, technical competence and overall knowledge of behavior-environment relations simply would not have been possible without Andy's explicit (as well as subtle) contingencies.

I also wish to extend my appreciation to David W. Schaal for his support, assistance, training and friendship, and for serving on my committee. Dave has been instrumental in teaching me about the finer discriminations involved with being a student at the graduate level. I would also like to thank Robert P. Hawkins for taking the time to serve on my committee and for offering valuable feedback regarding this thesis.

In addition, I wish to acknowledge Marla Virden and Lori Murray for their technical assistance with the experiment. Many sessions would not have begun on time without them! Our discussions regarding conceptual and methodological issues were valuable to me, and are appreciated. 
Table of Contents

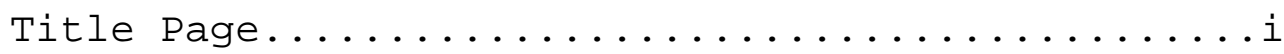

Acknowledgments.....................ii

List of Figures.....................

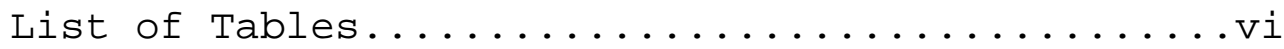

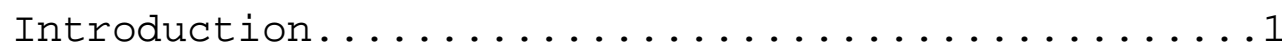

Literature Review....................

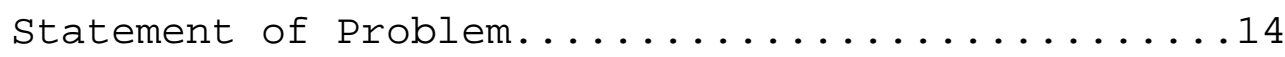

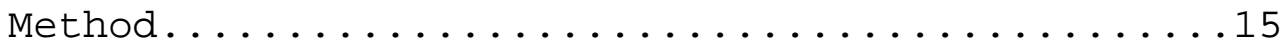

Subjects.........................

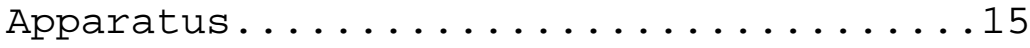

Procedure..................16

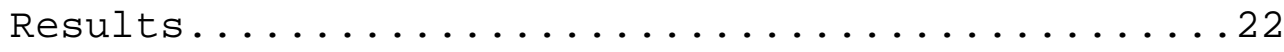

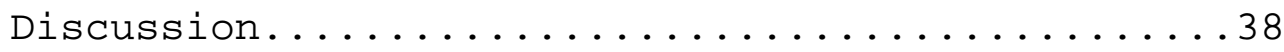

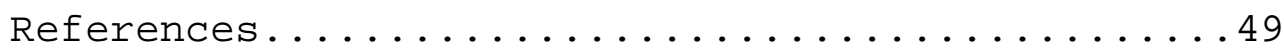

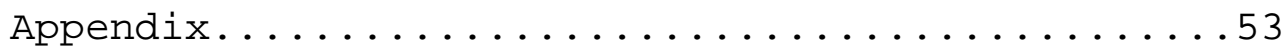

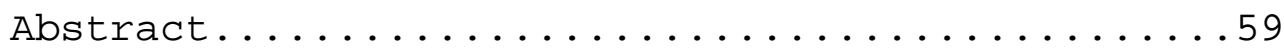

Approval Page......................60 
List of Figures

page

Figure 1: Responses per minute on the food key....24

Figure 2: Treadle presses per minute during first and last ten sessions of each

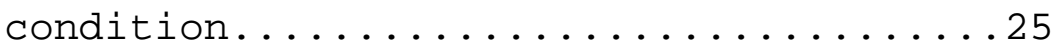

Figure 3: Treadle presses per minute during the first and last ten sessions of each condition as a function of the food

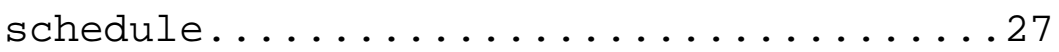

Figure 4: Cumulative treadle releases as a function of time across the first ten

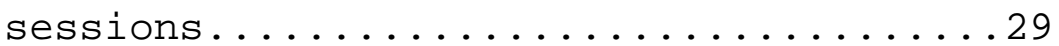

Figure 5: Treadle press durations across first ten

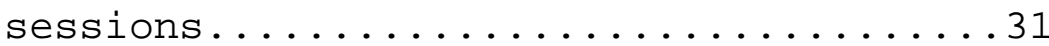

Figure 6: Cumulative treadle press duration as a function of time during the first session in the no-observing condition

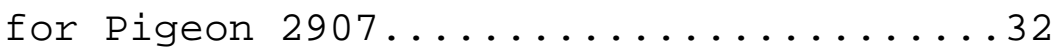

Figure 7: Number of treadle releases as a function of the number of food deliveries during

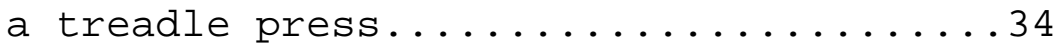




\section{List of Figures (continued)}

page

Figure 8: Frequency of obtained delays between

treadle onsets and food for Pigeons

2907,3987 and $5382 \ldots \ldots \ldots \ldots \ldots \ldots \ldots \ldots \ldots \ldots \ldots$

Figure 9: Frequency of obtained delays between

treadle onsets and food for Pigeons

5378,5970 and $5984 \ldots \ldots \ldots \ldots \ldots$

Figure 10: Frequency of obtained delays between

treadle onsets and $S+$ presentation....37 
$\mathrm{vi}$

List of Tables

page

Table 1: Sequence of conditions and number of sessions for each subject...........19 
Introduction

The experimental analysis of operant behavior is defined by the systematic investigation of the antecedent and consequent environmental events that maintain behavior. Within this framework, an operant class typically is selected by the experimenter and functionally defined responses are positively reinforced until response rates are steady from session-tosession. Until relatively recently, the experimental analysis of how behavior is established, from the first instance of a response to steady state, has been of secondary interest. The analysis of this transition state, termed response acquisition, attempts to determine under what conditions previously unreinforced behavior occurs, and is a useful complement to the study of how established behavior is maintained (Sidman, 1960). For example, the conditions that generate responding initially may exert effects on behavior in subsequent steady-state performance. In addition, how behavior is established in acquisition may in part be a function of prior schedules of reinforcement that maintained topographically similar responses. The analysis of conditions under which novel instances of behavior emerge therefore is a necessary component to the experimental analysis of behavior.

The novelty of a response may be described in various ways: 
changes in topography, location, or frequency of a response that exists, in some form, as a part of the organism's behavioral repertoire. In all methods of response acquisition certain operations enhance the establishment of the response. Historically, three of these operations that have been considered essential are reinforcer establishing operations, whereby putative reinforcers are made effective (e.g., food deprivation), temporal contiguity, and contingency (i.e., the dependent relation between a response and its consequence). Skinner (1953) emphasized the importance of temporal contiguity, or immediacy of reinforcement, in increasing the frequency of a response, contending that the more immediate the consequences the greater the amount of control over behavior. Although contiguity is conducive to both response acquisition and maintenance, immediacy of reinforcement of a response is not necessary for the acquisition of behavior. Utilizing an unsignaled delay of reinforcement procedure, response acquisition has been obtained in the absence of temporal contiguity (Critchfield \& Lattal, 1993; Dickinson, Watt \& Griffiths, 1992; Lattal \& Gleeson, 1990; Lattal \& Metzger, 1994; Lattal \& Williams, 1997; Wilkenfield, Nickel, Blakely and Poling, 1992), suggesting that contingency may be a sufficient condition for response acquisition. The studies that have addressed acquisition with delayed reinforcement, however, all have involved the arrangement of 
primary reinforcing consequences.

Reinforcers established through an organism's phylogenic history, such as food, water and the opportunity to engage in sexual behavior, are termed primary reinforcers. Appetitive stimuli, such as grain for pigeons or food pellets for rats, are used frequently in the experimental analysis of behavior because of the ease of their scheduling and delivery (Gleeson, 1991). These appetitive stimuli, when accompanied by the requisite establishing operations such as deprivation, then can be applied to obtain acquisition by reinforcing successive approximations to a predetermined response (Skinner, 1953). Other environmental events, however, derive their reinforcing function from their correlation with these appetitive stimuli and are termed conditioned reinforcers. Response acquisition in the absence or degradation of temporal contiguity has not been addressed with other than primary reinforcers.

One method of arranging the contingent delivery of conditioned reinforcement is the observing procedure (Wyckoff, 1952). In this procedure, responding initially is maintained by a multiple schedule of food delivery. In a multiple schedule, two or more component schedules alternate in some fashion with different stimuli correlated with each component. The schedule then is changed to a mixed schedule (i.e., the same stimulus is correlated with every component). A second response, termed the 
observing response, produces a brief stimulus change from the mixed stimulus to a stimulus correlated previously with that schedule of reinforcement. In previous studies, the conditions that maintain observing have been addressed. However, the conditions that establish and maintain the observing response all have involved immediate primary or conditioned reinforcement. The present study examined observing response acquisition with delayed reinforcement when the reinforcer was established through its correlation with a previously established reinforcer. In this manner, the role of conditioned reinforcement in response acquisition was addressed.

\section{Literature Review}

To establish an operant, the response may be either trained or simply allowed to contact the contingency between it and the reinforcer. As mentioned previously, the differential reinforcement of successive approximations, or shaping, is one method for establishing an operant. If the response occurs at a non-zero frequency prior to training, however, primary reinforcement alone also is used to increase the probability of the response, with shaping necessary only to alter the topography, duration or intensity of the response.

Response acquisition also has been demonstrated in the absence of both explicit training (see Gleeson, 1991 for a review) and response-reinforcer contiguity. The techniques to 
establish responding in lieu of shaping that have been employed include priming, imitation and prompting (Gleeson, 1991).

Priming includes "baiting" the operandum with food or making a response more likely by altering the operandum itself, as by employing a key extension (Lattal \& Gleeson, 1990). Acquisition also may occur from imitation, whereby responding is established as a result of attending to a response-reinforcer relation that exists for another organism. In addition, the organism simply may be placed in the experimental context until exploratory activity or a target response contacts the operandum.

Through correlation with primary reinforcement, stimuli can function as reinforcers and when they do they are termed secondary, or conditioned, reinforcers. To address the question of whether response acquisition with conditioned reinforcement can be obtained reliably, a procedure is needed whereby the response is neither established nor maintained directly by a reinforcer established previously through an organism's phylogenetic history.

To delineate the parameters relevant to the investigation of response acquisition with delayed conditioned reinforcement, the following issues will be discussed in further detail: response acquisition with delayed reinforcement, conditioned reinforcement, and response acquisition with conditioned reinforcement. 


\section{Response Acquisition With Unsignaled}

\section{Delayed Primary Reinforcement}

When using the previously described techniques for response acquisition, acquisition is rapid when there is temporal contiguity between the response and reinforcer. Employing a delay of reinforcement procedure, Lattal and Gleeson (1990) demonstrated that discrete responses (key pecking in pigeons and bar-pressing or omnidirectional lever presses with rats) were established without shaping or other explicit training of the response. Subjects first were trained only to eat from a hopper or magazine. Then a delay procedure was effected that consisted of a tandem fixed-ratio (FR) [or variable-interval (VI)] differential-reinforcement-of-other-behavior (DRO) 30-s schedule of reinforcement. Each response during the delay reset the $30-\mathrm{s}$ DRO timer, so that $30 \mathrm{~s}$ always separated a response and a reinforcer. Under this procedure, response acquisition was obtained. Lattal and Gleeson (1990) employed several control procedures to rule out potential confounding sources of control over responding. By manipulating food location, the possible orientation bias resulting from the food source and work panel being proximally located also was shown not to contribute to the obtained effect.

The effect of unsignaled delays ranging from 2 to $64 \mathrm{~s}$ on the acquisition of lever-pressing in rats was investigated by 
Dickinson, Watt and Griffiths (1992). Responses that occurred during the delay had no programmed consequences, that is, the delays were non-resetting. As in Lattal and Gleeson (1990), the response was not trained; the subjects simply were placed in the experimental chamber and allowed to contact the relation between responding on a lever and food delivery after a delay period. Although the use of non-resetting delays did not prevent adventitious contiguity between the response and the reinforcer after the first response, acquisition was obtained at all nominal delay values in the absence of explicit response shaping.

Wilkenfield et al. (1992) demonstrated that with a resetting delay responding was reliably established with resetting delays of up to 16 seconds. Resetting delays of $32 \mathrm{~s}$ controlled less consistent responding than that controlled by shorter delays, which suggests that the acquisition demonstrated by Dickinson et al. (1992) under 64-s delays was partly a function of adventitious reinforcement. The individual subject data reveal few differences as a function of resetting versus nonresetting delay procedure other than greater variability around the mean for nonresetting delays (Wilkenfield et al., Figures 2, 4, 6). Acquisition with delayed reinforcement also has been obtained with different operants (Critchfield \& Lattal, 1993; Lattal \& Gleeson, 1990; see Lattal \& Metzger, 1994), delay procedures (Wilkenfield et al., 1992) and body weights (Lattal \& 
Williams, 1997). The cumulative results of these studies suggest that response acquisition with delayed reinforcement is a general, reliable finding, with and without adventitious contiguity between response and reinforcer. Thus, immediate reinforcement is not necessary for response acquisition but shorter delays do lead to higher rates of responding.

\section{Conditioned Reinforcement}

When a discriminative stimulus evokes responding that subsequently is reinforced in the presence of that stimulus it is termed a conditioned reinforcer. Conditioned reinforcement has been suggested to play a role in a number of behavioral phenomena such as chained-schedule performance, choice behavior and secondorder schedule performance (Gollub, 1977; Fantino, 1977).

In chained schedules, immediate conditioned reinforcement is provided by the stimulus change correlated with the next schedule, or link in the chain. Response rates typically are lower than if the same schedule terminated in immediate primary reinforcement. Delays to conditioned reinforcment in chained schedules, however, are reduced in a manner similar to delays to primary reinforcement (Royalty, Williams \& Fantino, 1987).

To assess the conditioned reinforcing effect of a stimulus, another procedure often utilized involves presenting that stimulus contingent upon responding in the absence of primary reinforcement. This "extinction responding" approach (cf. 
Bugelski, 1938) results in a brief period of responding where the conditioned reinforcer is produced, followed by a typical extinction curve (cf. Williams, 1994).

Procedures that address the role of conditioned reinforcement, however, typically do not accurately elucidate potential conditioned reinforcers because the discriminative and reinforcing functions of the stimulus are confounded. The extent to which a stimulus functions as a conditioned reinforcer depends on the correlation between that stimulus and a primary, or backup, reinforcer. Because the extinction-responding procedure removes the backup reinforcer the conditioned reinforcer is weakened to the point that it no longer maintains behavior. Although chained schedules arrange for the re-pairing of the primary and conditioned reinforcer, responding is maintained jointly by both the primary and conditioned reinforcers. The response that produces the conditioned reinforcer also is necessary to produce the primary reinforcer. Due to these concerns, the observing procedure is the most frequently used method to address the contribution of conditioned reinforcement alone to response maintenance.

Observing Responses

Unlike the situation in other procedures which arrange for conditioned reinforcement, an observing response is not necessary to produce the primary reinforcer, and the conditioned reinforcer 
is re-paired intermittently with the primary reinforcer. In Wyckoff's (1952) procedure, pigeons stood on a pedal to produce discriminative stimuli correlated with a multiple fixed-interval (FI) extinction (EXT) schedule.

If no responding occurred on the pedal, the schedule remained a mixed schedule--i.e., the stimuli correlated with FI and EXT remained the same. Wyckoff (1952) termed the pedal-pressing behavior "observing responses" because the sole consequence of a pedal-press response was the production of discriminative stimuli, hence responding maintained by "observing" the multiple schedule components.

Establishing observing behavior involves preliminary training (following magazine training) with a multiple schedule of reinforcement. The multiple schedule then is changed to a mixed schedule, and brief presentations of the discriminative stimuli formerly correlated with the multiple schedule are made contingent on responding to another operandum.

Most investigations of observing responses involve multiple schedules that include an extinction component. In such procedures maintenance of observing behavior, and perhaps also acquisition, may be impeded by the aversiveness of the stimulus correlated with extinction (Fantino, 1977; Gollub, 1977). Bowe and Dinsmoor (1983) investigated the sources of control in maintaining observing behavior using two perch operanda. The 
observing response that produced either $S+$ or $S-$ (Exp. 1), depending on which component of a mixed VI EXT schedule was in effect. In accordance with the findings of Dinsmoor, Mueller, Martin and Bowe (1982), S+ was produced more frequently than $\mathrm{S}-$. When an observing response produced $S-$ the subject immediately stepped off the perch, whereas when $S+$ was produced the perch was continuously depressed, suggesting that $S-$ functioned to punish observing. These results demonstrated that the production of the S+ is responsible primarily for the maintenance of observing, and suggest that variables that affect the discriminative and reinforcing functions of the $\mathrm{S}+$ (e.g. reinforcement rate in the presence of the stimulus) may affect observing behavior.

To investigate the effects of both different reinforcement rates and component durations correlated with the S+ on observing, Branch (1973) varied random-ratio (RR) schedule requirements from 50 to 400 and component durations from 1.25 to $320 \mathrm{~s}$. Only the extreme conditions, where the component duration was $1.25 \mathrm{~s}$ or the condition in which the RR value was 400, diminished observing responses. Branch's findings suggest that neither component duration nor schedule value "is a strong determinant of observing" (1973, p. 417).

Both key pecking (Branch, 1970; Branch, 1973; Kelleher et al., 1962) and treadle-pressing (Dinsmoor et al., 1982) have served as observing responses. In the majority of observing 
response procedures, the focus has been on the variables maintaining the behavior and not on how the behavior is established. Of the studies described above, only Dinsmoor et al. (1982) were concerned with the acquisition of observing. The procedure was similar to that used by Bowe and Dinsmoor (1983), in that perches also were used as the observing operanda. Although responding on the perches was not explicitly trained, the perches were available during all phases of the experiment, including baseline conditions. To determine which of the two perches would serve as the observing operandum, the experimenters selected the perch stood on the least during baseline. The amount of responding on the perches prior to a contingency suggests that responses were perhaps inevitable due to their size (14 cm long, with a gap of only $1.7 \mathrm{~cm}$ between them) and location relative to the hopper $(5.5 \mathrm{~cm}$ from the work panel and $3.2 \mathrm{~cm}$ from the floor). When the contingency between responding and conditioned reinforcement production was effected, most observing occurred during the positive stimulus (S+). Thus "acquisition" in this context more accurately refers to the establishment of control by the contingency, or of differential responding between the two operanda.

\section{Response Acquisition With Conditioned Reinforcement}

The above data suggest that stimuli correlated with reinforcement generally function similarly to primary 
reinforcement in terms of their effects on response maintenance. Primary reinforcement is used to establish new behavior. Stimuli correlated with primary reinforcement also might be effective in establishing new behavior, lending support to the earlier suggestion of functional similarities between primary and conditioned reinforcement.

Second-order autoshaping is a case of response acquisition with conditioned reinforcement in that intermittent re-pairing of the second-order CS with either the US or with the first-order CS (if it also is occasionally paired with the US) increases responding not previously emitted (see Rashotte, 1981, for a review). Patterson and Winokur (1973) repeatedly paired a tone with food for pigeons, after which the tone was utilized as a US in an autoshaping preparation, where the US immediately followed a presentation of a lit key. Key pecking was established, yet soon fell to zero levels due to the absence of the primary reinforcer. In essence, the 5-s tone used by Patterson and Winokur (1973) served as a first-order CS which did not elicit a discrete response. However, when paired with a keylight, the tone effectively functioned as a second-order CS capable of eliciting the unconditional response--pecking. Rashotte, Griffin and Sisk (1977) also demonstrated that contiguous pairing of a CS with a second, neutral, stimulus (keylight) resulted in a secondorder CS that elicited key pecking. 
Operant response acquisition with conditioned reinforcement has received only limited analysis. Zimmerman (1957) used a buzzer to establish lever-pressing in rats after several sessions where the buzzer was paired with water delivery. Training included gradually increasing the intermittence with which the buzzer and primary reinforcer were paired, yet each water delivery was preceded by the buzzer. Due to this intermittent pairing procedure, lever-pressing first was established (with $\mathrm{CRF}$, then maintained at low levels without a primary reinforcer as a consequence (i.e., with the buzzer as the consequence for responding). In this procedure, an operant was established and maintained in a manner similar to that which occurs in chained schedules. However, as in the extinction-responding approach to assessing the effectiveness of a conditioned reinforcer, Zimmerman's procedure did not include further re-pairing of the primary and secondary reinforcer. Hence, the buzzer was no longer a reinforcer; it merely was in the process of functioning as a discriminative stimulus for not responding on the lever. The response maintenance reported by Zimmerman was the decreasing response rate occurring during this transition.

\section{Statement of Problem}

Response acquisition in the absence of explicit training occurs under a variety of conditions where primary reinforcement is employed, either when such reinforcement is immediate or 
delayed (Lattal \& Gleeson, 1990). Conditioned reinforcement has been suggested to determine response maintenance in chained schedules (Royalty, Williams \& Fantino, 1987; Gollub, 1977; Fantino, 1977) and observing procedures (e.g., Wyckoff, 1952). Acquisition of either respondents or operants with conditioned reinforcement has been investigated only infrequently (Rashotte, 1982; Rashotte, et al., 1977; Patterson \& Winokur, 1973; Zimmerman, 1957). The present study used an observing procedure to examine response acquisition with unsignaled, delayed conditioned reinforcement.

Method

\section{$\underline{\text { Subjects }}$}

Six male White Carneau pigeons maintained at 75\% of ad libitum weight served as subjects. Two subjects (2907 and 3987) were exposed previously to a variety of drug discrimination procedures. The other 4 were experimentally naive. Each was housed individually with free access to water and health grit.

\section{Apparatus}

A two-key pigeon operant chamber with a work area of $32.5 \mathrm{~cm}$ X $31 \mathrm{~cm}$ X $38 \mathrm{~cm}$ was used. The chamber was housed in a $34 \mathrm{~cm} \mathrm{X} 61$ cm X $40 \mathrm{~cm}$ sound-attenuating enclosure, with a ventilation fan that also helped to mask additional extraneous noise. Only the right response key, requiring approximately $0.15 \mathrm{~N}$ to operate, was used. The $2 \mathrm{~cm}$ diameter key was located $26 \mathrm{~cm}$ from the floor 
of the chamber and $9 \mathrm{~cm}$ from the right wall and could be transilluminated white, red or green. A response lever, $5 \mathrm{~cm}$ in width, protruded $2 \mathrm{~cm}$ from the work panel and was located $8 \mathrm{~cm}$ from the floor and $6 \mathrm{~cm}$ left of the hopper. During observing conditions, an L-shaped treadle, which required approximately .25 $\mathrm{N}$ to operate, was suspended from the response lever. The treadle was $5 \mathrm{~cm}$ wide at the lever and widened to $7 \mathrm{~cm}$ at the foot. The foot of the treadle was $7 \mathrm{~cm}$ wide and protruded $5 \mathrm{~cm}$ from the base. When in place, the treadle foot was approximately $2 \mathrm{~cm}$ from the floor of the chamber. Reinforcement was $3-s$ access to a solenoid-operated hopper which was raised into a $5 \mathrm{~cm}$ X $5 \mathrm{~cm}$ aperture centered on the work panel $11 \mathrm{~cm}$ from the floor. General illumination (except for the duration of reinforcement) was provided at all times by a $4 \mathrm{~cm}$ X $4 \mathrm{~cm}$ houselight whose center was $6 \mathrm{~cm}$ from the right wall and $5.5 \mathrm{~cm}$ from the floor. A Tandy 1000 ex computer operated with Med-PC ${ }^{\circledR}$ software was used to program contingencies and record experimental events. A cumulative recorder (Gerbrands model C3) recorded treadle presses, food deliveries and discriminative stimuli presentations. Both the computer and cumulative recorder were located in an adjacent room.

Procedure

\section{Pretraining}

Each of the 4 experimentally naive pigeons was magazine 
trained until it reliably approached and ate from the food hopper immediately following its presentation. For the remainder of the experiment, sessions were conducted 7 days a week. Following the completion of magazine training, the key was transilluminated green and key pecking was established with each subject by the differential reinforcement of successive approximations. A session then was conducted which arranged for 5 reinforcer deliveries each on FR 1, FR 3, FR 5, FR 10 and FR 15. At least one session each then was conducted using a VI 15-s, VI 30-s and VI 60-s schedule. Pigeons 2907 and 3987 were introduced to the chamber with the terminal VI 60-s schedule in effect.

\section{Multiple Schedule Training}

A multiple (mult) VI 60-s extinction (EXT) schedule of reinforcement was effected following the final session of pretraining. The response key was transilluminated green and red, respectively, when the VI schedule and EXT were in effect. The multiple schedule components were scheduled randomly with the constraint that neither VI nor EXT components occurred more than 3 times in succession. Unless indicated otherwise, each component lasted $80 \mathrm{~s}$ and sessions ended after 60 components (30 VI and $30 \mathrm{EXT})$. The VI component interval values were selected with replacement from a list of 20 intervals generated using the progression described by Fleshler and Hoffman (1962). This condition remained in effect until response rates were judged 
stable by visual inspection and a discrimination ratio of .95 was observed in the last 3 consecutive sessions, where the discrimination ratio $=$

Responses in VI + Responses in EXT.

Due to time constraints, the mixed schedule was effected for Pigeon 5382 although a discrimination ratio was not reached after 33 sessions of multiple schedule training. The percentage Pigeon 5382's responses that occurred during the VI schedule typically was between 79 to $85 \%$

\section{Between Subject Comparisons}

The number of sessions conducted for each condition and the sequence of conditions for each subject are summarized in Table 1. There were two conditions for between subject comparisons: response acquisition with delayed reinforcement (observing condition) and extinction (no-observing condition), which are described below. Three subjects were exposed first to the observing condition (Pigeons 5378, 5970 and 5984) and three (Pigeons 2907, 3987, and 5382) to extinction first.

In the observing condition, the multiple VI60-s EXT schedule described above was changed to a mixed (mix) VI60-s EXT schedule, with the key transilluminated white during both components. Simultaneously, the treadle was introduced into the chamber. In this and all subsequent conditions involving the treadle, both treadle presses and treadle releases were recorded. Treadle 
Table 1

Sequence of Experimental Conditions and Number of Sessions for Each Subject

\begin{tabular}{|c|c|c|c|}
\hline \multirow[b]{2}{*}{ Subject } & \multicolumn{2}{|c|}{ Schedule Condition } & \multirow{2}{*}{$\begin{array}{l}\text { Number of } \\
\text { Sessions }\end{array}$} \\
\hline & Key & Treadle & \\
\hline \multirow[t]{6}{*}{2907} & VI $60 \mathrm{~s}$ & - & 2 \\
\hline & Mult VI $60 \mathrm{~s}$ EXT & - & 20 \\
\hline & Mix VI 60 s EXT & EXT with COD & 34 \\
\hline & & Observing & 26 \\
\hline & & EXT with COD & 14 \\
\hline & & Observing & 5 \\
\hline \multirow[t]{5}{*}{3987} & VI $60 \mathrm{~s}$ & - & 3 \\
\hline & Mult VI $60 \mathrm{~s}$ EXT & - & 18 \\
\hline & Mix VI $60 \mathrm{~s}$ EXT & EXT with COD & 22 \\
\hline & & Observing & 17 \\
\hline & & EXT with COD & 23 \\
\hline \multirow[t]{7}{*}{5382} & VI $15 \mathrm{~s}$ & - & 2 \\
\hline & VI $30 \mathrm{~s}$ & - & 2 \\
\hline & VI $60 \mathrm{~s}$ & - & 5 \\
\hline & Mult VI $60 \mathrm{~s}$ EXT & - & 33 \\
\hline & $\operatorname{Mix}$ VI $60 \mathrm{~s}$ EXT & EXT with COD & 26 \\
\hline & & EXT without COD & 15 \\
\hline & & Observing & 10 \\
\hline \multirow[t]{9}{*}{5378} & VI $15 \mathrm{~s}$ & - & 2 \\
\hline & VI $30 \mathrm{~s}$ & - & 2 \\
\hline & VI $60 \mathrm{~s}$ & - & 5 \\
\hline & Mult VI $60 \mathrm{~s}$ EXT & - & 20 \\
\hline & $\operatorname{Mix}$ VI 60 EXT & Observing & 10 \\
\hline & & EXT without COD & 30 \\
\hline & & EXT with COD & 48 \\
\hline & & Observing & 31 \\
\hline & & EXT with COD & 8 \\
\hline \multirow[t]{8}{*}{5970} & VI $15 \mathrm{~s}$ & - & 4 \\
\hline & VI $30 \mathrm{~s}$ & - & 4 \\
\hline & VI $60 \mathrm{~s}$ & - & 3 \\
\hline & Mult VI $60 \mathrm{~s}$ EXT & - & 16 \\
\hline & Mix VI 60 s EXT & Observing & 15 \\
\hline & & EXT without COD & 24 \\
\hline & & EXT with COD & 33 \\
\hline & & Observing & 19 \\
\hline
\end{tabular}


Table 1 (continued)

\begin{tabular}{|c|c|c|c|}
\hline \multirow[b]{2}{*}{ Subject } & \multicolumn{2}{|c|}{ Schedule Condition } & \multirow{2}{*}{$\begin{array}{l}\text { Number of } \\
\text { Sessions }\end{array}$} \\
\hline & Key & Treadle & \\
\hline \multirow[t]{8}{*}{5984} & VI $15 \mathrm{~s}$ & - & 2 \\
\hline & VI $30 \mathrm{~s}$ & - & 1 \\
\hline & VI $60 \mathrm{~s}$ & - & 6 \\
\hline & Mult VI $60 \mathrm{~s}$ EXT & - & 20 \\
\hline & Mix VI 60 s EXT & Observing & 19 \\
\hline & & EXT with COD & 19 \\
\hline & & EXT without COD & 32 \\
\hline & & Observing & 26 \\
\hline
\end{tabular}


release constituted the response, and treadle onsets produced no consequences. In the observing condition, each treadle release initiated a 10-s unsignaled, resetting delay; hence a tandem FR 1 DRO 10-s schedule was effected on the treadle operandum. When the delay interval ended, the keylight was changed from white to green if the VI component was in effect; if EXT was in effect following the delay, then no stimulus change occurred. The green discriminative stimulus remained on the key for $10 \mathrm{~s}$, after which the key again was transilluminated white. During the 10-s conditioned reinforcer presentation, however, the mixed stimulus was reinstated with the onset of an EXT component.

The EXT components in the initial session of the observing condition were shortened to $8 \mathrm{~s}$ to increase the likelihood that the first response on the treadle produced a consequence. Beginning with the second session, EXT components again were $80 \mathrm{~s}$ in duration. At least 10 sessions of the observing condition were conducted.

In the no-observing condition, treadle releases produced no consequences. All other aspects of the procedure were the same as the observing condition. At least 10 sessions were conducted. In both conditions, a $3-$ s changeover delay (COD) prevented food deliveries from occurring contiguously with a treadle press. The first peck following a treadle release initiated the COD, irrespective of the next scheduled food delivery. A response on 
the food key could only produce the next food delivery following the completion of the COD if a treadle press had occurred since the last peck.

\section{Within Subject Comparisons}

The two conditions described above subsequently were reversed for each subject. Thus, the observing contingency was removed for Pigeons 5378, 5970 and 5984, and was implemented for Pigeons 2907, 3987 and 5382. The conditions then were reversed again, except for Pigeon 5382, whose rates of treadling fell to near-zero rates and did not recover.

A treadle release produced two consequences: the initiation of the COD with the next key peck, and the initiation of the 10-s delay to conditioned reinforcement. Because these events were produced by a treadle release only, it was for this reason that both presses and releases were recorded to determine treadle press durations, which potentially could affect the scheduling of experimental events. For example, if treadle press durations were relatively long, then scheduled events could occur while the treadle was depressed, because only the release of the treadle produced consequences.

An error occurred during the first reversal in the condition without the observing contingency, during which the COD did not function. Performance was stabilized before reinstating the COD. Pigeons 5378, 5970, 5984 and 5382 received the no-observing 
condition with and without the 3-s COD.

Results

Rates of key pecking in both components of the multiple and mixed VI EXT schedules during each condition are shown in Figure 1. Pecks to the food key were relatively constant across conditions. Response rates decreased for Pigeon 3987 with the introduction of the mixed schedule, and continued to decrease for the remainder of the experiment. When the introduction of the mixed schedule was accompanied by extinction on the treadle, key peck response rates were equal in both components, as the right graphs of Figure 1 (Pigeons 2907, 3987, and 5382) illustrate. However, when the observing condition was in effect and the mixed schedule initially was introduced, VI response rates were higher than those during EXT, as can be seen with Pigeons 5378, 5970 and 5984 in the left graphs of Figure 1.

\section{Treadle Press Response}

Between Subject Comparisons

For the three subjects that received the observing condition with the introduction of the mixed schedule (Pigeons 5378, 5970 and 5984), the observing contingency generated treadle pressing at levels comparable to those occurring in the absence of a contingency for treadle pressing (Pigeons 2907, 3987 and 5382). In summary, the data in Figures 2 (treadle releases per session) and 3 (treadle releases per minute) show that treadle presses 


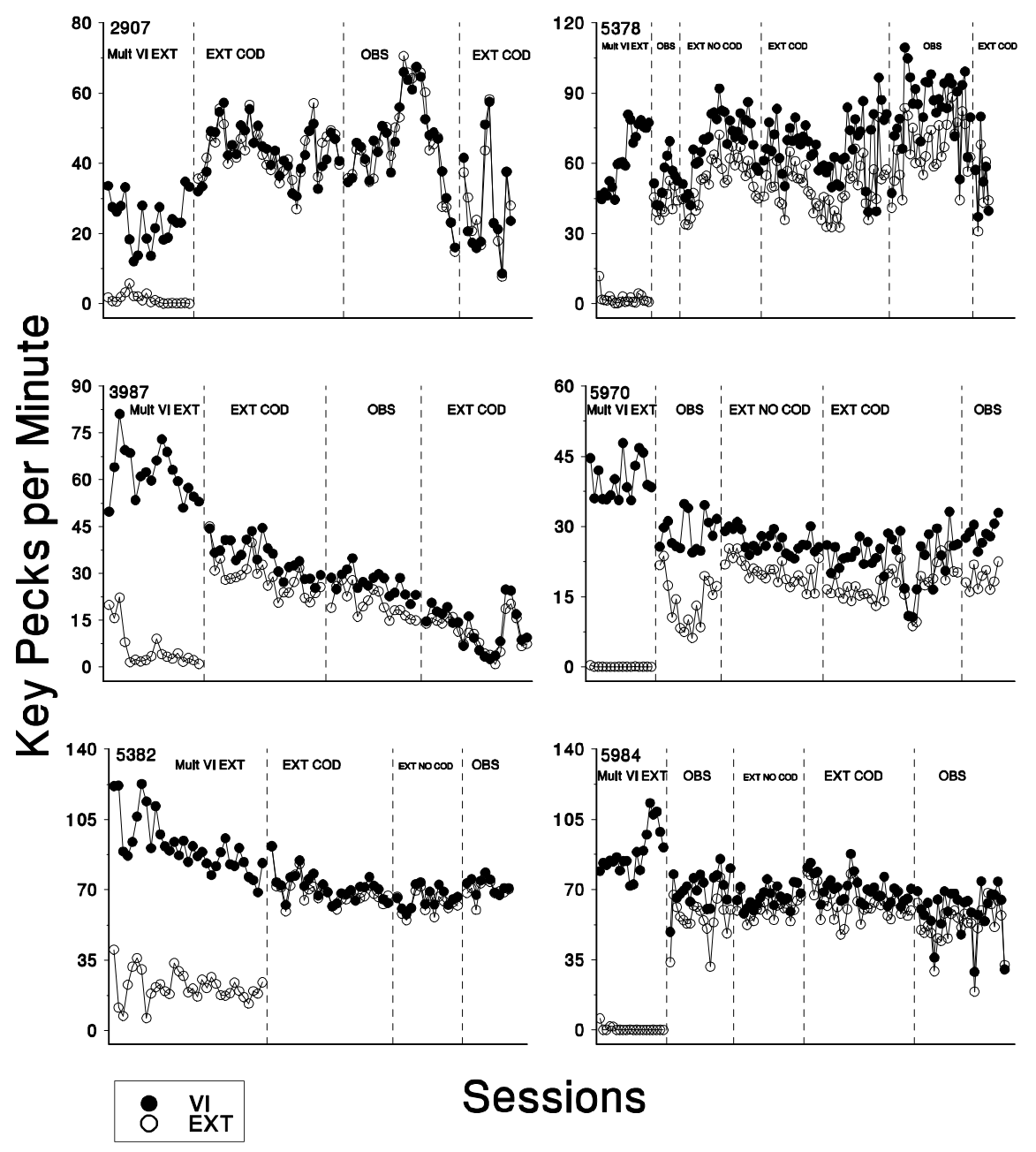

Figure 1. Responses per minute to the food key for all pigeons during the multiple schedule (mult VI EXT), observing (OBS) and no observing conditions with (EXT COD) and without (EXT NO COD) a 3-s COD. Note that different scales were used for each subject. The filled and open circles represent rates during VI and EXT components, respectively. Each data point represents the mean for one 80-minute session. VI rates were adjusted for food delivery time. 


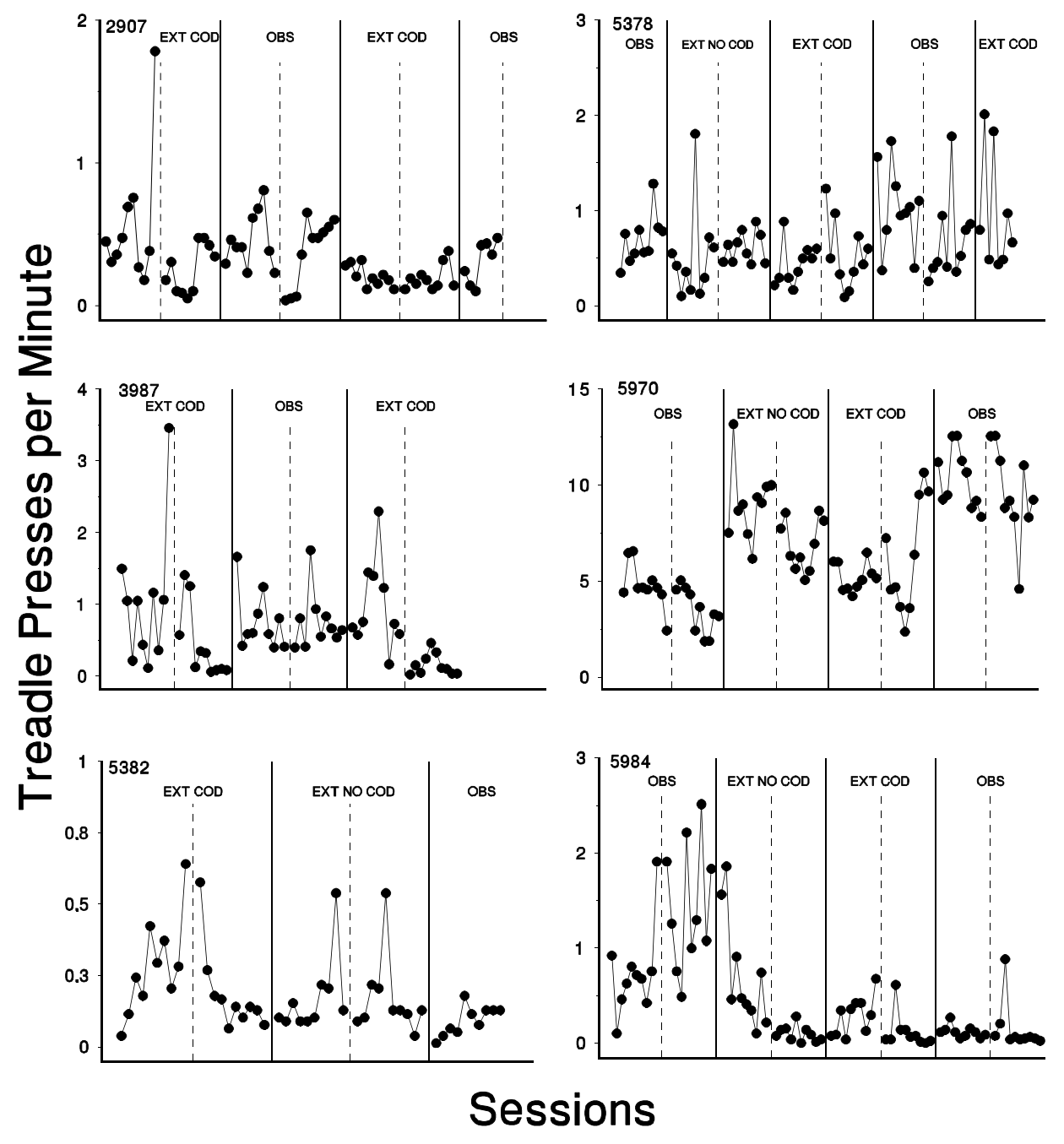

Figure 2. Treadle releases per minute for each subject during the first and last 10 sessions in each condition following multiple schedule training. Vertical solid lines denote condition changes. Data to the left of the vertical dashed lines are those rates that occurred in the first 10 sessions, and data to the right of the dashed lines are response rates in the final 10 sessions of the condition. 
were established and maintained when the observing contingency was in effect. However, responses on the treadle also were established and maintained at equivalent rates in the absence of the observing contingency, although there is some evidence that treadle pressing eventually was reduced in extinction conditions. The number of treadle presses emitted during the initial 10 sessions in which the treadle was available with (Pigeons 5378, 5970, 5984) or without (Pigeons 2907, 3987, 5382) the observing contingency were compared to determine if treadling in these two conditions differed significantly. The data were pooled across subjects to give 30 scores for each condition. A main effect of condition was not significant via a repeated measures ANOVA, F(2, 59) $=1.39, \underline{p}=.227$.

Within Subject Comparisons

The total number of treadle releases during each of the first and last ten sessions of each condition is shown in Figure 2 with different scales of the y-axis for each subject. Treadling was established and maintained for each pigeon during the first 10 sessions in which the treadle-press response was available.

When the observing condition replaced extinction, treadle pressing generally was unaffected for Pigeon 5382, and a small effect was evident for Pigeons 2907 and 3987. For these two subjects, the observing contingency increased treadling in the 


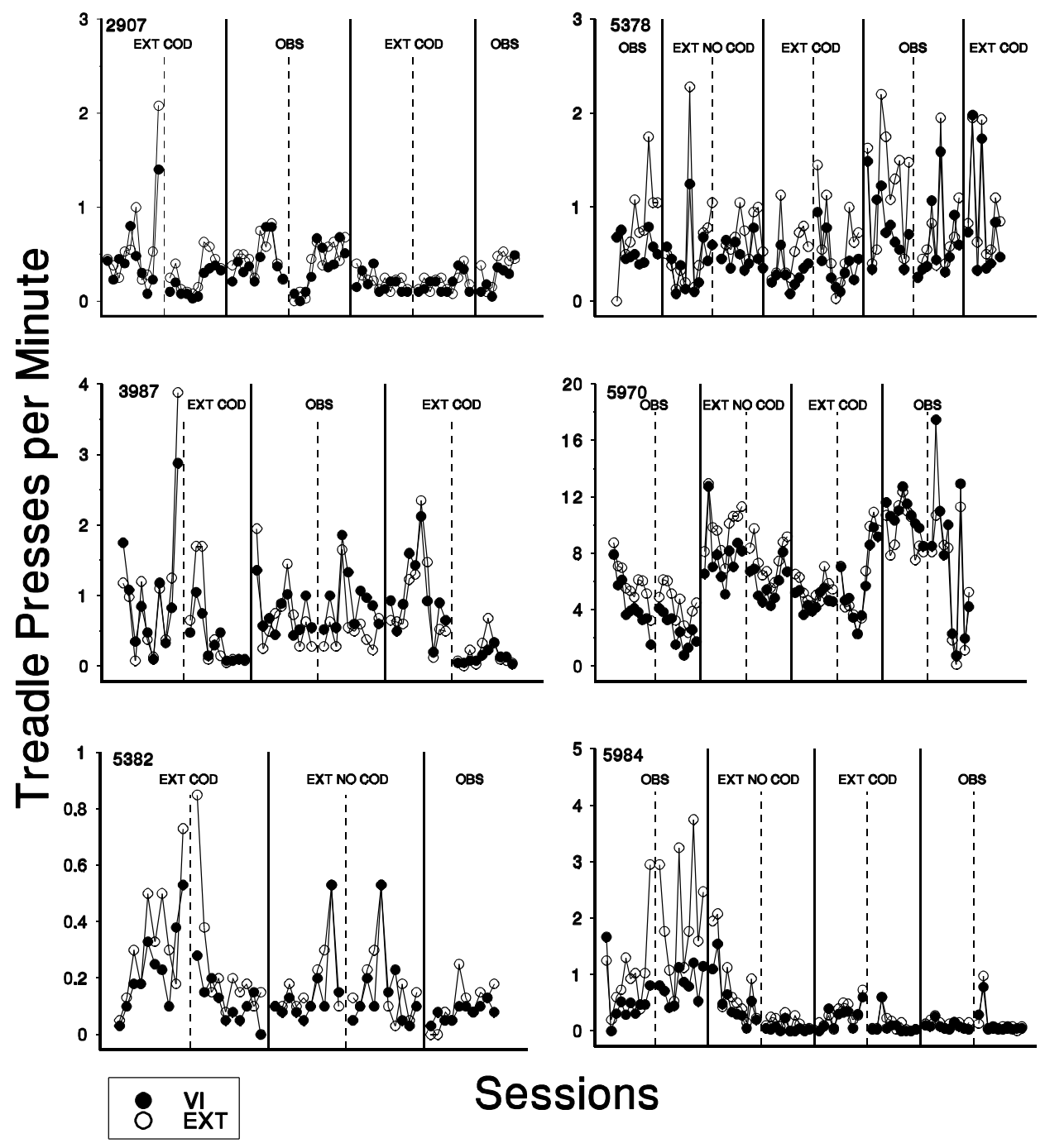

Figure 3. Treadle releases per minute for each subject during the first and last 10 sessions across all conditions in which the treadle was in place. The filled and open circles represent treadle rates during the VI and EXT components, respectively. Solid vertical lines denote condition changes. Data to the left of the vertical dashed lines are those rates that occurred in the first 10 sessions, and data to the right of the dashed lines are response rates in the final 10 sessions of the condition. Each data point represents the number of treadle releases in a component divided by the total time in that component. VI rates were adjusted for food delivery time. 
final 10 sessions relative to performance in the no-observing condition. For Pigeons 5378, 5970 and 5984, the number of treadle presses was changed by the removal of the observing contingency. This number increased for Pigeon 5970 and decreased for Pigeons 5378 and 5984. With the reinstatement of the observing condition, treadle presses per session increased for Pigeons 5378 and 5970, although treadle presses remained relatively high for Pigeon 5378 when the observing contingency was removed.

Treadle releases per minute during each component of the mixed schedule in the first and last 10 sessions of each condition are shown in Figure 3. Different scales were used for each subject. Generally, treadle rates were higher when the extinction component of the mixed VI EXT food schedule was in effect, although there were no programmed consequences for treadle presses that occurred in the extinction component. Cumulative treadle presses are shown in Figure 4 as a function of consecutive seconds of session time across the first 10 sessions of either the observing (Pigeons 5378, 5970 and 5984) or no observing (Pigeons 2907, 3987 and 5382) condition. Note that the scale for Pigeon 5970 is higher than in the other graphs. In addition, the times that experimental events occurred, as recorded by a computer, were lost for the fourth session for Pigeon 5970. The slopes of the functions for the 


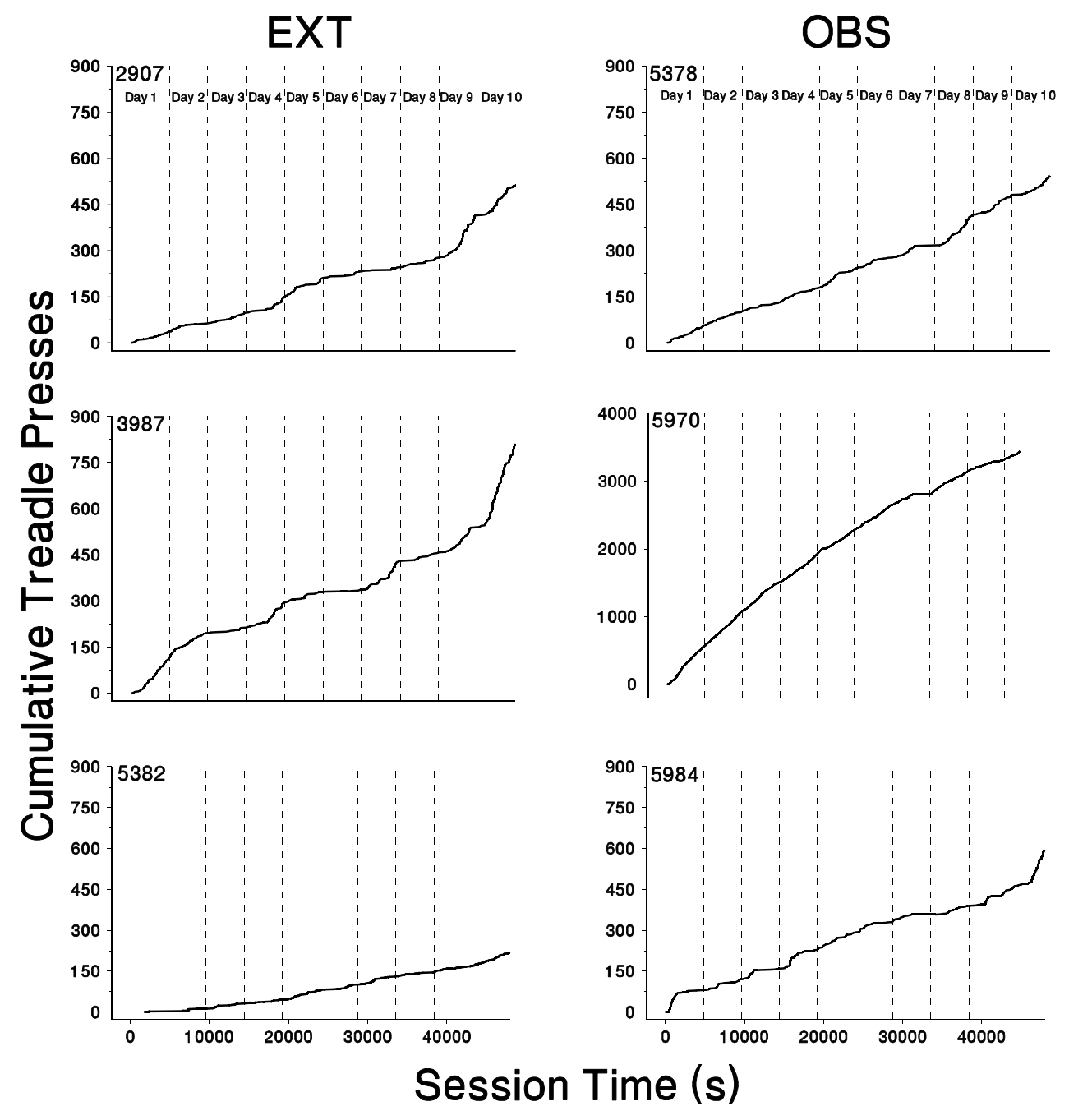

Figure 4. Cumulative treadles presses are displayed as a function of session time in seconds for each subject across the first 10 days in either the observing (right column) or no-observing condition (left column). Dashed lines indicate the end of a session. Note that a different scale was used for Pigeon 5970. The event times of Session 4 for Pigeon 5970 were lost. As a result, the function shown for Pigeon 5970 reflects Sessions 1, 2, 3, 5, 6, 7, $8,9,10$ and 11 . 
subjects first exposed to the observing condition do not differ systematically from those in the EXT column, although the function for Pigeon 5382 shows relatively less acceleration.

\section{Treadle Press Duration}

Treadle pressing occurred in the absence of a contingency; therefore, as discussed previously, treadle press durations were examined. A duration was defined as the time in seconds between a treadle press and a treadle release. Programmed events, as well as key pecking, potentially could occur during relatively long durations, because treadle onsets produced no consequences. Treadle press durations across the first 10 sessions are shown for each subject in Figure 5. The x-axis scales differ because each subject emitted a different number of treadle presses during the first 10 sessions. Most durations were less than $5 \mathrm{~s}$; however, the range included durations of less than $1 \mathrm{~s}$ to durations exceeding 2 minutes.

Analyses were undertaken to demonstrate the potential adventitious delivery of food after a treadle onset, but before a treadle release, and to determine whether subjects could stand on the treadle at one side of the work panel and reach the food key simultaneously. To determine the temporal contiguities between stepping on the treadle (treadle onsets) and programmed events, delays between onsets and both food deliveries and conditioned reinforcer deliveries were obtained. 


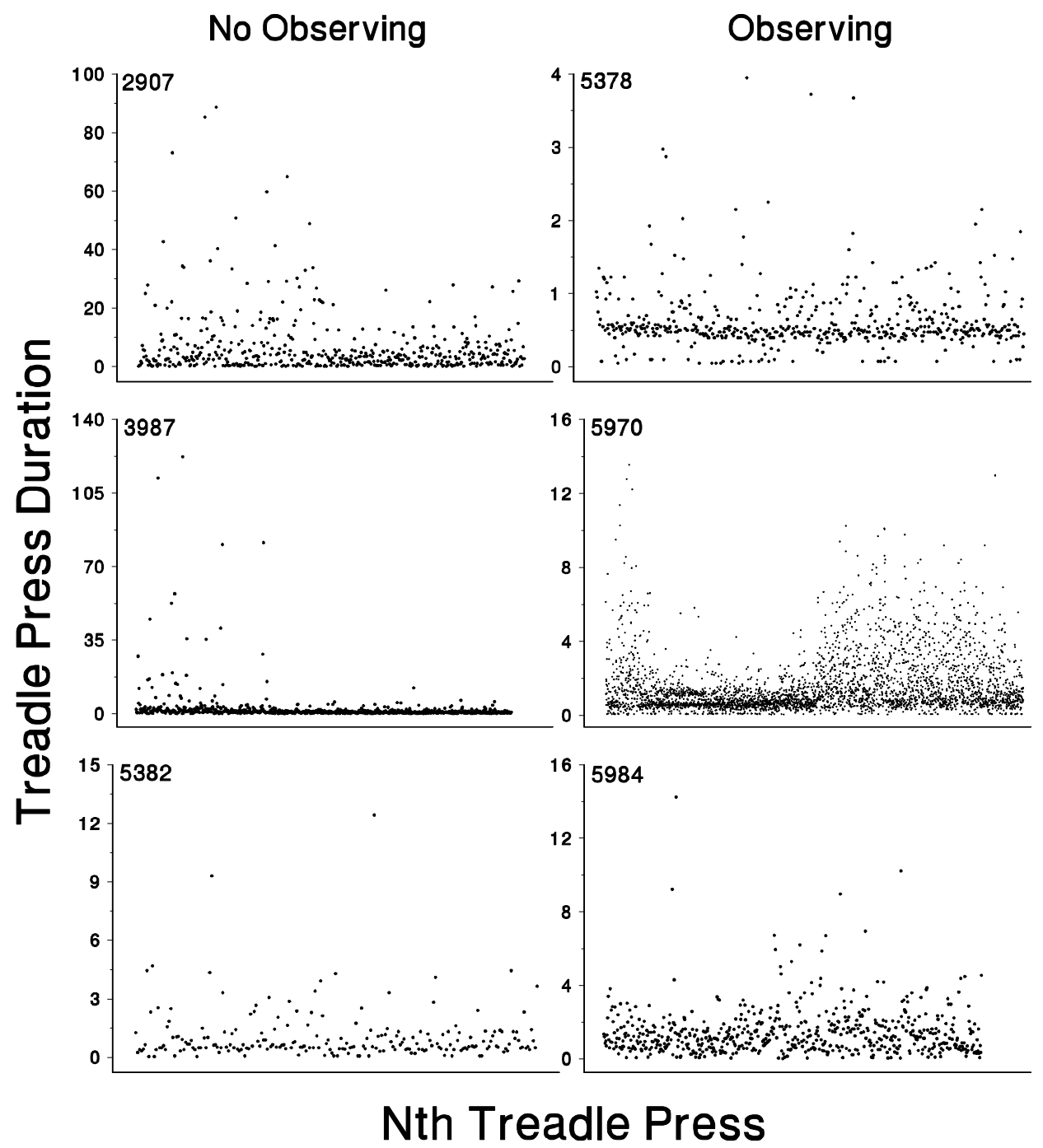

Fiqure 5. Treadle press durations in seconds are shown as a function of cumulative treadle presses for the first 10 sessions of either the observing (right column) or no-observing (left column) condition. Note that different scales were used for each subject. 


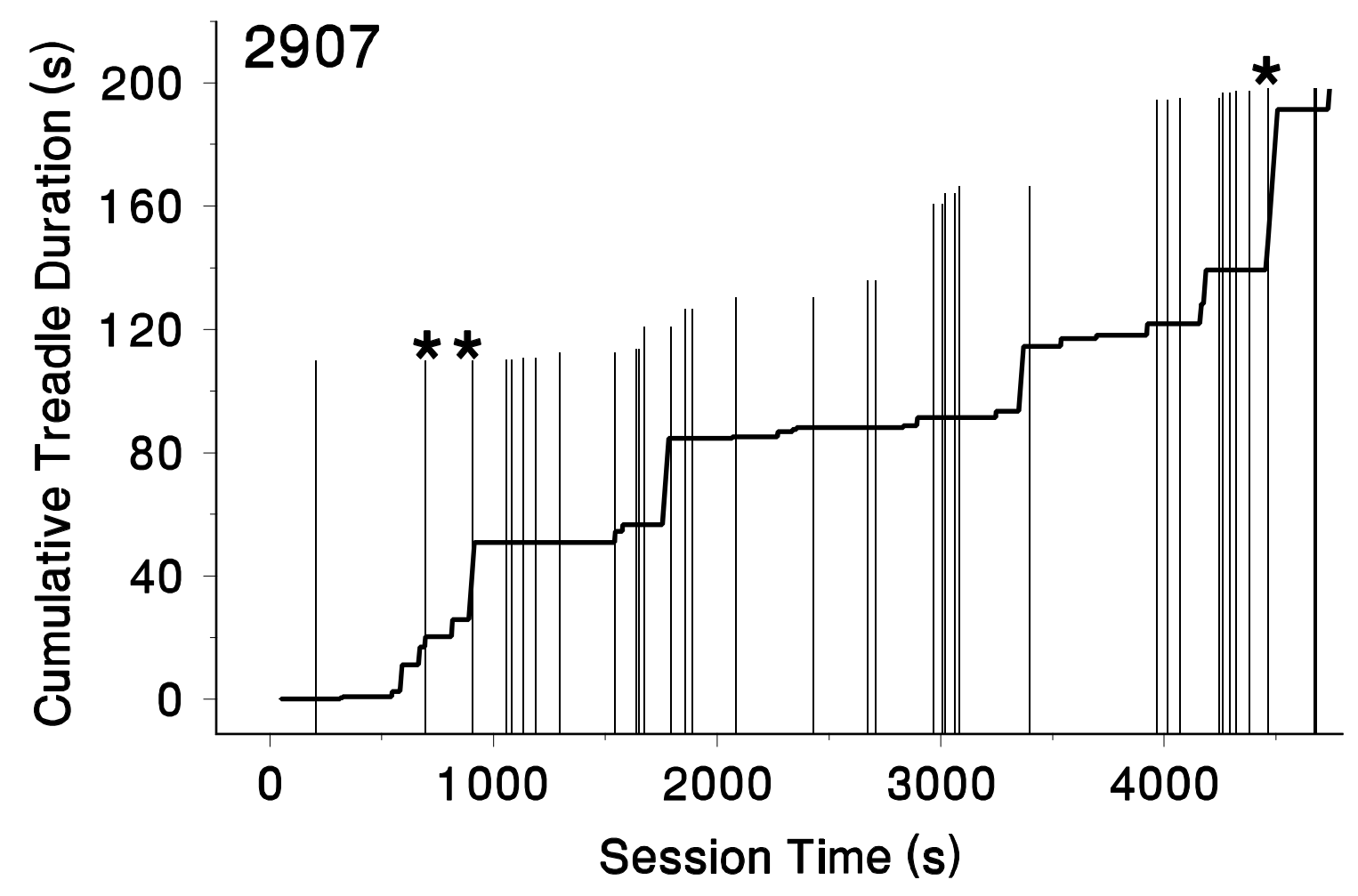

Figure 6. Cumulative treadle duration in seconds is shown as a function of session time in seconds for Pigeon 2907 during the first session of the no-observing condition. The function is displaced upward for the amount of time in seconds that the treadle was held down. Each treadle press during the session is represented. The vertical lines indicate food deliveries. The asterisks mark the vertical lines that crossed the function while the function is displaced upward, indicating that the reinforcer was delivered while the treadle was depressed. 
In Figure 6, cumulative treadle press duration is plotted as a function of time for Pigeon 2907 during the first session in which the treadle was in place. The vertical lines indicate food deliveries, and the asterisks mark those food deliveries that occurred during a treadle press. In Figure 7 the total number of treadle presses during each session are shown as a function of the number of food deliveries that were delivered during the session while the treadle was depressed. As in Figure 5, due to the variability in the number of treadle presses, different scales were used. The data display a general increasing trend in treadle presses as the number of food deliveries while the subject stood on the treadle increased for Pigeons 3987 and 5970 . The frequencies of all obtained delays from treadle onsets to food deliveries are shown in Figures 8 and 9. The median number of delays between onsets and food were greater than $10 \mathrm{~s}$. In accordance with the programmed COD, the minimum delay between a treadle onset and a food delivery would be the treadle press duration plus the 3-s COD. However, with 5 out of 6 subjects, a food delivery occurred less than 3 s following a treadle onset in conditions in which the COD was in effect.

Similarly, during the observing condition, the minimum delay between a treadle onset and the presentation of $\mathrm{S}+$ was the treadle press duration plus the 10-s resetting delay. The frequencies of obtained delays between onsets and $\mathrm{S}+$ 


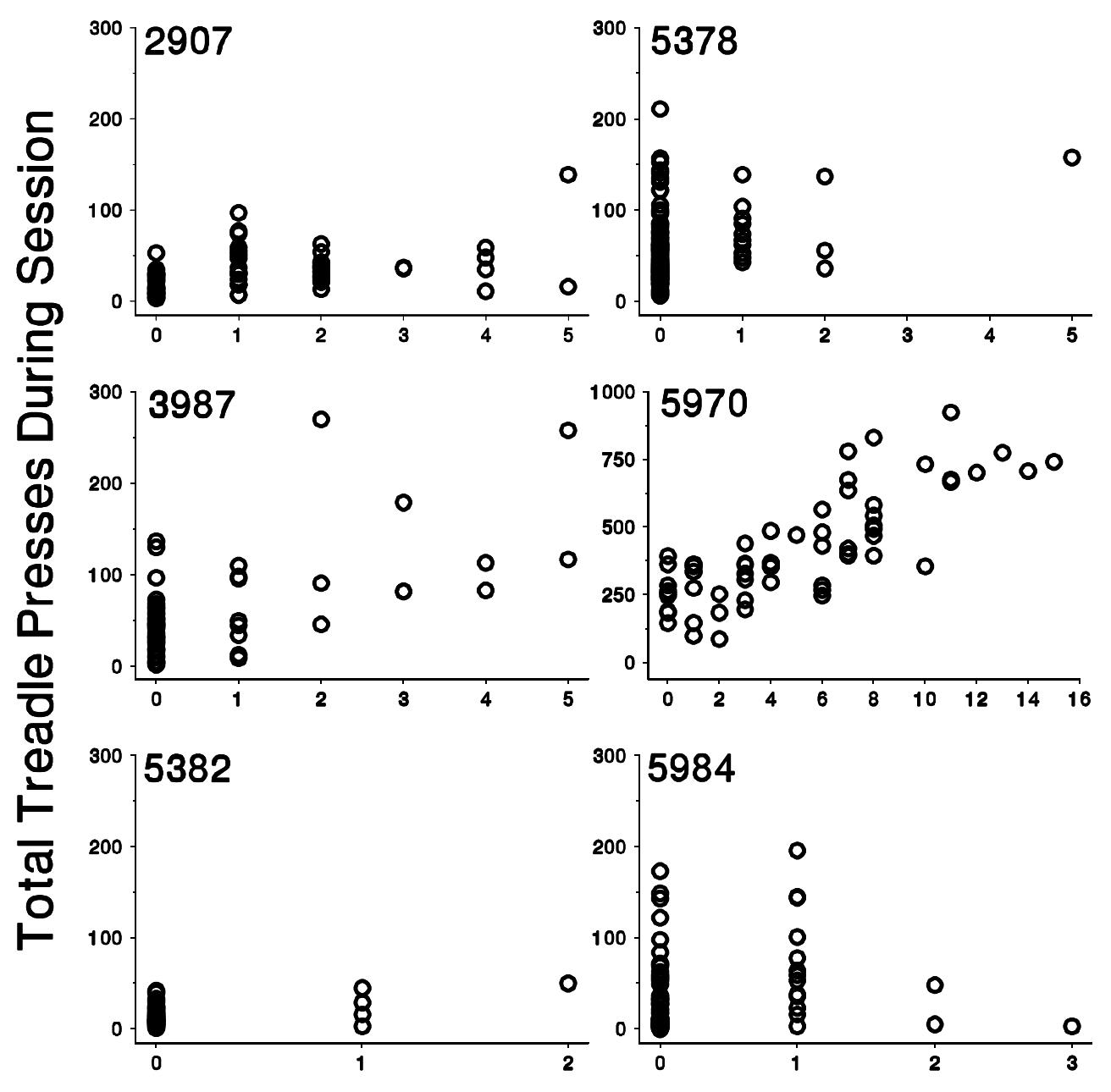

Food Deliveries During Treadle Press

Figure 7. Scatterplot of the number of treadle releases during a session as a function of the number of food deliveries that occurred while the treadle was held down. Note that different scales are used for each subject. 


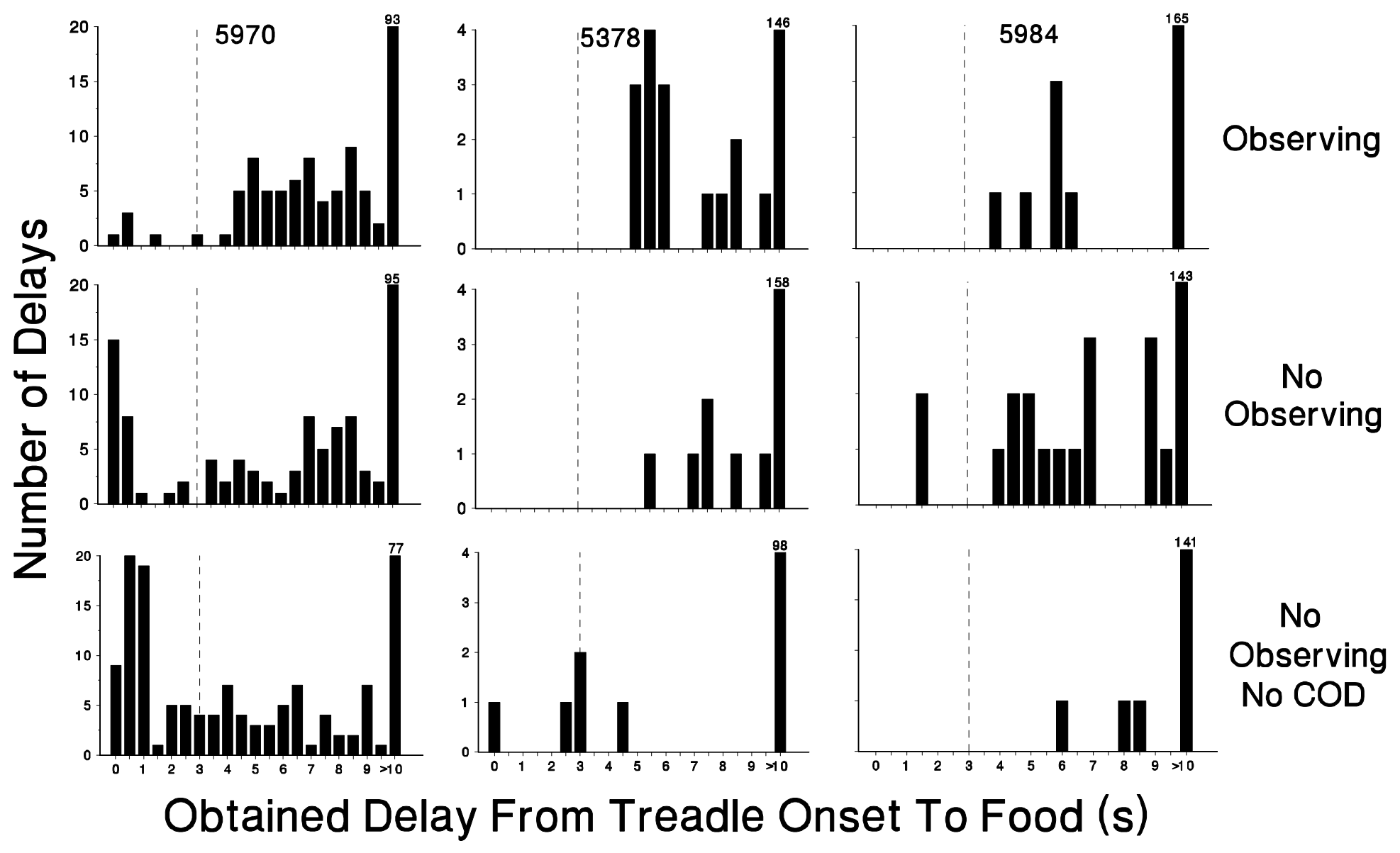

Figure 8. The number of all obtained delays between treadle onsets to food deliveries are shown for Pigeons 2907, 3987 and 5382 across each condition with the treadle available. The number of delays in the overflow bin (all delays greater than 10 seconds) is shown above the bar. Delays were tabulated using bins of 0.5 s. 


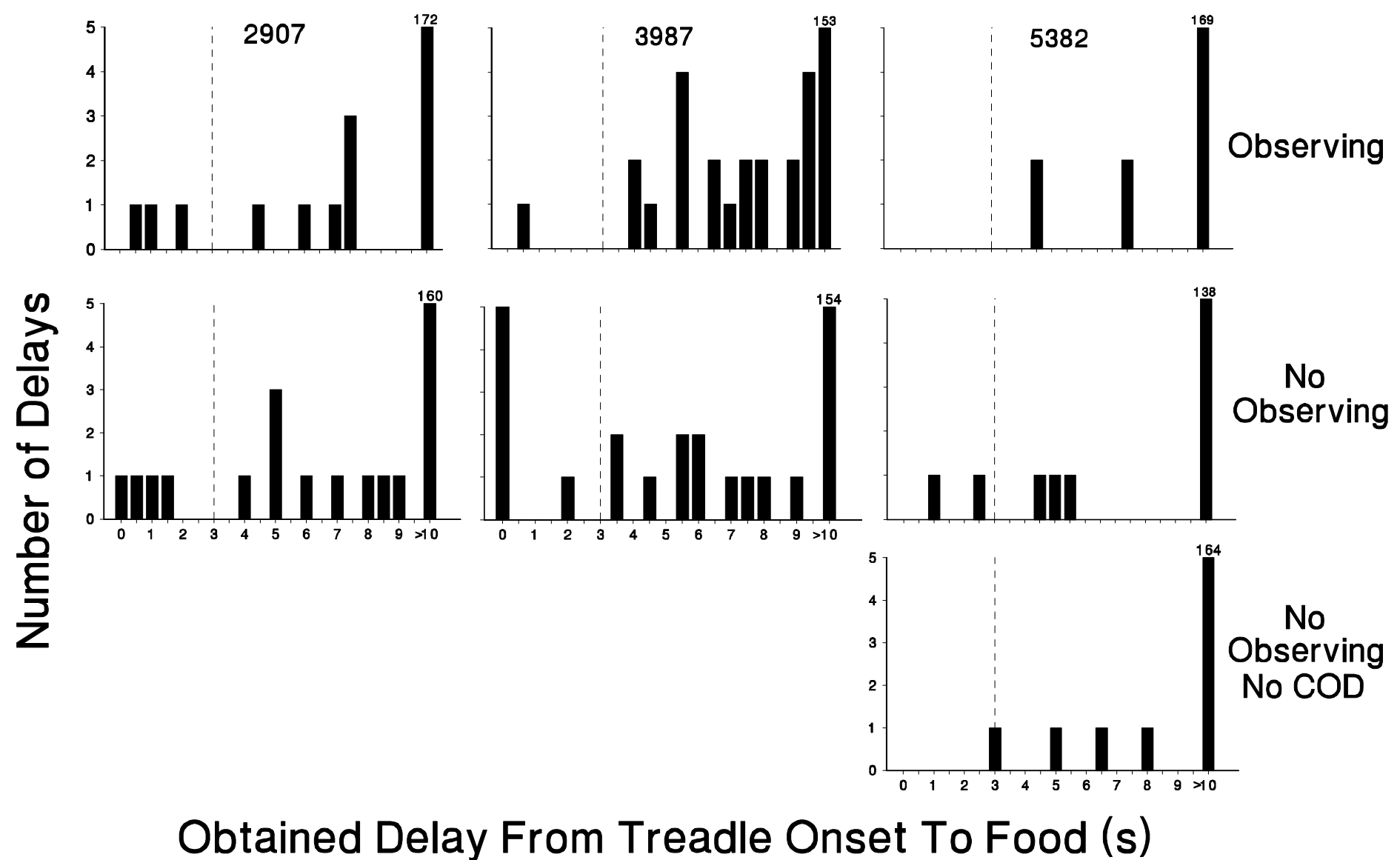

Fiqure 9. The number of all obtained delays between treadle onsets to food deliveries are shown for Pigeons 5378, 5970 and 5984 across each condition with the treadle available. The number of delays in the overflow bin (all delays greater than 10 seconds) is shown above the bar. Delays were tabulated using bins of 0.5 s. Note that a different scale was used for Pigeon 5970. 

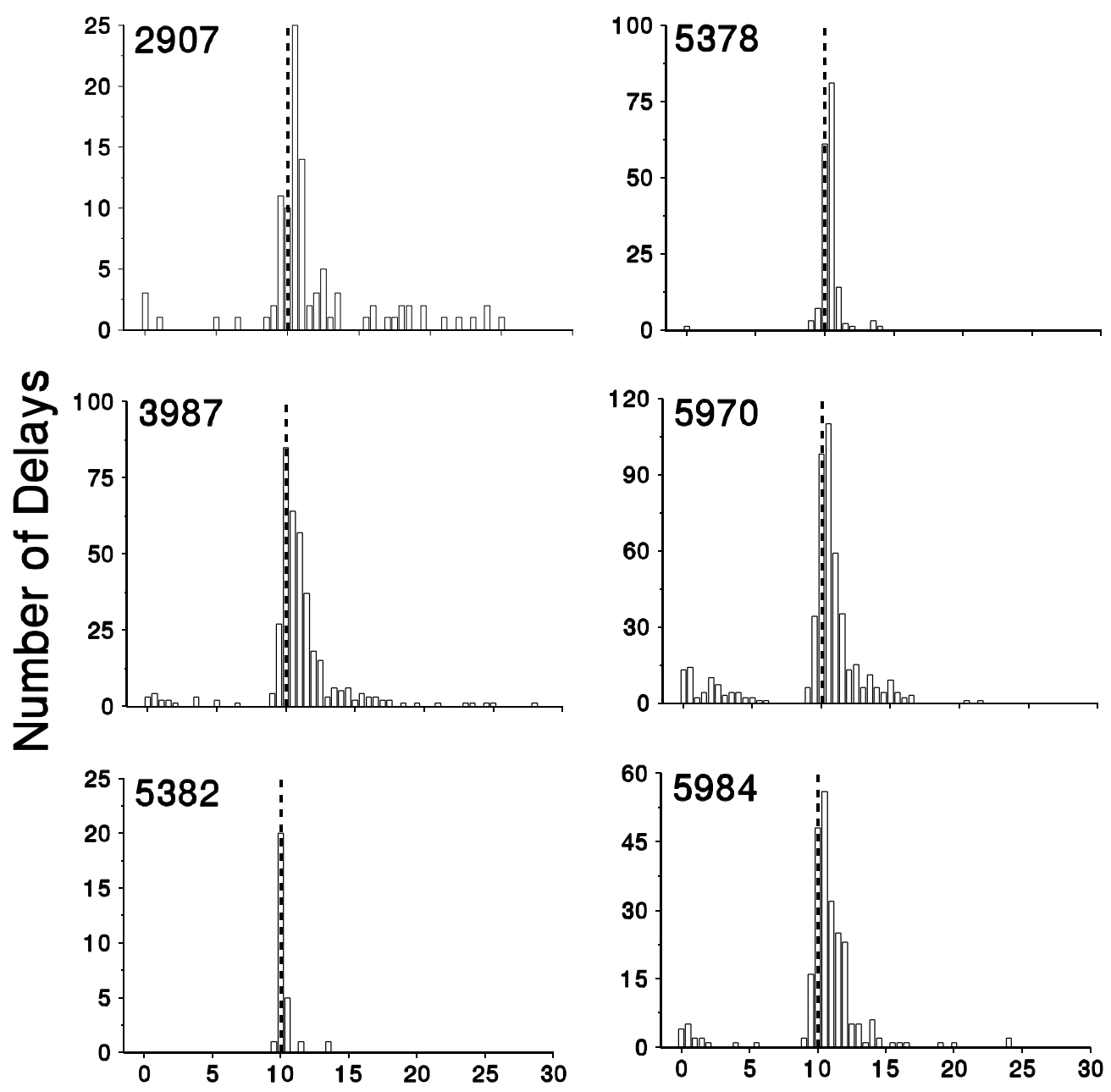

Obtained Delay From Treadle Onset To S+ (s)

Fiqure 10. Number obtained delays between treadle onsets and conditioned reinforcer deliveries for each subject during the observing condition. Delays greater than $30 \mathrm{~s}$ are not shown. Delays were tabulated using bins of $0.5 \mathrm{~s}$. Note that different scales are used for each subject. 
presentations are displayed in Figure 10. The median of obtained delays for all Pigeons was between 10-12 s. In general, subjects stepped on the treadle, held it down for 0-2 s, stepped off of the treadle, and $10 \mathrm{~s}$ later the $\mathrm{S}+$ was presented. However, the absolute range included delays less than $1 \mathrm{~s}$. Under these circumstances, the subject stepped on the treadle, stepped off of the treadle, and (before the $\mathrm{S}+$ presentation) stepped on the treadle again. Because only treadle offsets reset the $10-s$ delay, these onsets produced no consequences, and the conditioned reinforcer could be delivered contiguously with an onset. Relatively short delays between onsets and conditioned reinforcement occurred most frequently with Pigeons 2907, 3987, 5970 and 5984

\section{Discussion}

Treadle-pressing was established equally in the presence and absence of the observing contingency. The results of the present study therefore cannot be taken as evidence for response acquisition with delayed conditioned reinforcement and do not extend previous findings of response acquisition with delayed primary reinforcement (Critchfield \& Lattal, 1993; Dickinson, et al., 1992; Lattal \& Gleeson, 1990; Lattal \& Metzger, 1994; Lattal \& Williams, 1997; Wilkenfield, et al., 1992; Williams, 1996) to delayed conditioned reinforcement. Several features of the current procedure potentially contributed to the failure to 
extend these findings to response acquisition with delayed conditioned reinforcement. In addition to the delayed conditioned reinforcement arranged by the observing contingency, other potential sources of reinforcement of treadle pressing occurred in all conditions. Treadle location, the alternation of schedule components, the observing procedure as a choice procedure, and the effectiveness of the S+ as a conditioned reinforcer also will be examined in the following sections to assess the low rates of treadling in the observing condition.

\section{Unscheduled Consequences of Treadling}

Short Delays to Conditioned Reinforcement

The observing contingency arranged for the delivery of conditioned reinforcement following a 10 -s resetting delay. The delay was initiated by the release of the treadle, or treadle offset. The response of stepping onto the treadle, or treadle onset, produced no consequences. Theoretically, the 10-s delay could be initiated with a complete treadle press (i.e., onset and offset) followed by an onset. The $10 \mathrm{~s}$ would continue to elapse until either the S+ delivery or until a treadle offset. If a subject stood on the treadle for at least $10 \mathrm{~s}$ after the delay had been initiated, then the $\mathrm{S}+$ would be produced while the subject stood on the treadle. As Figure 10 shows, obtained delays from onsets to $\mathrm{S}+$ presentations occasionally were short, particularly with Pigeons 3987, 5970 and 5984. In addition, 3 
obtained delays from 0-1 s occurred for Pigeon 2907.

Incidentally, Pigeons 5970 and 5984 consistently made the highest number of treadle presses per session, and Pigeon 3987 emitted the highest rates of treadle pressing of the 3 pigeons exposed initially to the no-observing condition.

Short Delays to Primary Reinforcement

Responses on the treadle also may have been maintained partly by the adventitious delivery of primary reinforcement. Figures 8 and 9 show that food occasionally was delivered after a treadle onset and before a treadle offset, indicating that key pecks were emitted while subjects stood on the treadle. If the behavior that occurs between an onset and release (i.e., "standing on the treadle") is conceptualized as an operant, then these short obtained delays to food may have served to adventitiously maintain "standing" on the treadle. Standing is achieved only by stepping on the treadle; thus, a response chain, beginning with an onset and terminating with an offset, may have increased in frequency due to the delivery of food during the "standing" link of the chain.

\section{Treadle Location}

In addition to potential adventitious reinforcement for treadling during VI, the high rates of treadling during EXT components of the mixed schedule may have in part been a function of the location of the observing operandum. Subjects engaged in 
panel-directed behavior for nearly the entire session. This included "pacing" along the work panel, particularly during long interreinforcement intervals and when an EXT component was in effect. The high rates of treadle pressing in the no-observing condition, therefore, can be attributed in part to general paneldirected activity. A treadle press therefore may be an inappropriate response to assess response acquisition with delayed conditioned reinforcement, at least when placed near the food key, because treadle presses could not be attributed to the contingency alone.

\section{Component Durations and Alternation}

Another potential source of control of the high rates of treadle pressing in the no-observing condition involves the scheduling of the VI and EXT components. Each component lasted for $80 \mathrm{~s}$, and no more than 3 could occur in succession. Thus, an EXT component was in effect for either 80,160 or $240 \mathrm{~s}$. Treadle pressing may have been partly controlled by the adventitious production of the next VI component. This suggests that, with a richer VI schedule, adventitious food-schedule production would increase, because the period of reinforcement would be more easily discriminable.

\section{Observing Behavior as Choice}

The above discussion suggests that perhaps the observing procedure can be characterized as a choice procedure: a Findley 
concurrent multiple VI EXT mixed VI EXT, with the observing response as the changeover response. Switching from the mixed schedule to the multiple schedule is reinforced when a relatively higher rate of reinforcement is produced, or when a short delay to food follows. This characterization is consistent with the findings of Branch (1970), who found a drastic reduction in observing when a 2-s COD was implemented between a response on the observing key and food delivery.

The above observations provide possible explanations for the establishment of treadle pressing without a reinforcement contingency for doing so. If the observing rates obtained are operant level, then, the question remains as to why the observing contingency was ineffective in establishing the observing response. The absence of a clear demonstration of control by the observing contingency also may be a function of the ineffectiveness of the $\mathrm{S}+$ as a conditioned reinforcer.

\section{Effectiveness of $S+$ as a Conditioned Reinforcer}

VI Reinforcement Rate

The rate of food delivery was arranged by a multiple or mixed VI 60-s EXT schedule. Thus, on average 3-s access to grain was produced once per minute in the VI components. If a richer VI schedule was used during multiple schedule training, then the stimulus correlated with the VI theoretically could control relatively more responding to produce that stimulus in the 
observing condition (Branch, 1970). Conversely, a leaner VI during multiple schedule training could result in a weaker conditioned reinforcer. Although Branch (1973) demonstrated that different $R R$ schedule requirements did not affect observing, the rate of food delivery with interval schedules may be a source of control over observing rates. Branch (1970) showed that pigeons observed at higher rates during VI 30-s components in both mixed VI 30-s VI 120-s and mixed VI 30-s EXT schedules.

The Mixed Stimulus as an S+

Food delivery was correlated with both multiple (green) and mixed (white) stimuli. The mixed stimulus also could function as a conditioned reinforcer, because any stimulus that can serve as a CS will function as a conditioned reinforcer (Fantino, 1977). If less primary reinforcement occurred in the presence of the green key than the white key during mixed schedule conditions, then perhaps the relative reinforcing efficacy of the green key also was less. If the white key functioned as a more effective conditioned reinforcer, then the observing response that removed it and replaced it with a weaker reinforcer would be less likely. Figures 1 and 3 show that the white key was discriminative and/or reinforcing for both key pecking and treadle pressing. Figure 1 shows that the introduction of the mixed schedule did not systematically decrease rates of pecking. Figure 3 shows that rates of treadling generally were higher in EXT than in VI. 
Because the S- (red keylight) could not be produced, a treadle press in EXT was not followed by a stimulus change (i.e., the mixed stimulus remained on the key. This situation perhaps could result in the mixed stimulus acquiring aversive properties. The disparate treadle rates suggest, however, that the white key did not function as an aversive stimulus. This suggests further that, if indeed the white key was a more effective reinforcer, then the $\mathrm{S}+$ functioned as an $\mathrm{S}-$ relative to the white key, consistent with the findings of Branch (1970), that observing is maintained at a higher rate by the production of a stimulus correlated with a higher relative rate of reinforcement. In addition to the potentially weak reinforcing potential of the multiple stimulus, the presence of a long delay between the response and the multiple stimulus presentation may have resulted in a contingency that did not support response acquisition. The Length of the Delay to Conditioned Reinforcement

In the present study the 10-s delay to conditioned reinforcement may have impeded acquisition. Delays of up to $64 \mathrm{~s}$ have been used to establish responding with delayed primary reinforcement, and acquisition functions typically are shallower as the delay to primary reinforcement increases. Response rates maintained by primary reinforcement may be decreased less by delays, however, than similar rates maintained by conditioned reinforcement, although no studies have addressed this directly. 
Although Royalty, et al. (1987) suggest that the rate-suppressive effects of unsignaled delays in chained schedules on responding maintained by conditioned reinforcement are similar to that with primary reinforcement, chained-schedule performance is maintained by both primary and conditioned reinforcement. It is possible, therefore, that behavior maintained by conditioned reinforcement alone (e.g., observing) is weaker, in terms of the ratesuppressive effects of delay, than that maintained by primary reinforcement.

Magnitude of the Conditioned Reinforcer

In addition to immediacy and rate of reinforcement, another variable that affects response rates is reinforcer magnitude. In the present study, a 10-s change in keycolor from white to green served as the conditioned reinforcer. If a longer duration is conceptualized as a larger magnitude of conditioned reinforcer, then perhaps longer durations produce higher rates of observing. A longer S+ duration also increases the likelihood that food is delivered in the presence of the $\mathrm{S}+$, thus maintaining the efficacy of the conditioned reinforcer by re-pairing it with the primary reinforcer. It therefore is conceivable that the 10-s presentation of the green light was of insufficient duration to establish the observing response. In support of this notion, some of the conditioned reinforcer presentations were less than $10 \mathrm{~s}$, because the mixed stimulus was reinstated with the onset of 
an EXT component during the $10 \mathrm{~s}$.

The above discussion on the potential ineffectiveness of the conditioned reinforcer provides possible explanations for why treadle pressing during the observing condition was equal to or less than responding in the absence of the contingency. As with the discussion regarding the high operant level of treadling in the no-observing condition, the potential explanations for the ineffectiveness of the putative conditioned reinforcer suggest that the observing response may be usefully characterized as a changeover response in a choice procedure. To produce higher rates of switching to the multiple schedule, it may be necessary to increase the reinforcement rate in the VI, thus increasing the probability that a short delay to food will follow a changeover. It may be sufficient, however, to change the distribution of intervals in the VI schedule to include more relatively short intervals to increase the likelihood that food is re-paired with the conditioned reinforcer. In addition, the magnitude of the conditioned reinforcer should be increased to a duration that would ensure that food is correlated more frequently with the multiple stimulus than the mixed stimulus. Increasing the magnitude of the conditioned reinforcer also increases the rate of food in the presence of the multiple stimulus, and thus the likelihood of a short delay to food following a switch from the mixed schedule to the multiple schedule. 


\section{Implications}

The acquisition and response maintenance of novel behavior has been demonstrated with delayed primary reinforcement. In addition, response maintenance by conditioned reinforcement has been demonstrated under a variety of conditions (Bowe \& Dinsmoor, 1983; Branch, 1970; Branch, 1973; Dinsmoor, et al., 1982; Kelleher, et al., 1962; Kendall \& Gibson, 1965; Royalty, et al., 1987; Wyckoff, 1952), and acquisition with conditioned reinforcement has been shown in second-order autoshaping procedures (e.g., Patterson \& Winokur, 1973; Rashotte, 1981; Rashotte, et al., 1977). If conditioned reinforcement functions in the same manner as primary reinforcement, that is to say, the stimulus selects a response by increasing its frequency of occurrence, then it follows that novel instances of behavior can be established when the response produces delayed conditioned reinforcing consequences. However, in the present study, the confounds discussed render it difficult, if not impossible, to assess unambiguously the contribution of the observing contingency to the establishment and maintenance of a novel response with delayed conditioned reinforcement. To arrange such an assessment, the procedure employed in the present study should be modified to ensure the temporal and spatial separation of the two operanda. In addition, any response on the treadle operandum should affect the delay to conditioned reinforcement as well as 
the COD, such that both onsets and offsets reset the delays. This would ensure that all behavior that is necessary to the completion of the observing response is temporally removed from reinforcing consequences. 
References

Bowe, C.A. \& Dinsmoor, J.A. (1983). Spatial and temporal relations in conditioned reinforcement and observing behavior. Journal of the Experimental Analysis of Behavior, 39, 227-240. Branch, M.N. (1970). The distribution of observing responses during two VI schedules. Psychonomic Science, 20, 5-6.

Branch, M.N. (1973). Observing responses in pigeons: Effects of schedule component duration and schedule value. Journal of the Experimental Analysis of Behavior, 20, 417-428.

Brown, P.L. \& Jenkins, H.M. (1968). Autoshaping the pigeon's key-peck. Journal of the Experimental Analysis of Behavior, $11,1-8$

Bugelski, R. (1938). Extinction with and without sub-goal reinforcement. Journal of Comparative Psychology, 26, 121134

Critchfield, T.S. \& Lattal, K.A. (1993). Acquisition of a spatially defined operant with delayed reinforcement. Journal of the Experimental Analysis of Behavior, 59, 373-387.

Dickinson, A., Watt, A. \& Griffiths, W.J.H. (1992). Freeoperant acquisition with delayed reinforcement. The Quarterly Journal of Experimental Psychology, 45B, 241-258. Dinsmoor, J.A., Mueller, K.L., Martin, L.T. \& Bowe, C.A. (1982). The acquisition of observing. Journal of the Experimental Analysis of Behavior, 38, 249-263. 
Fantino, E. (1977). Conditioned reinforcement: Choice and information. In W.K. Honig \& J.E.R. Staddon (Eds.), Handbook of Operant Behavior (pp. 313-339). Englewood Cliffs, NJ: Prentice Hall.

Fleshler, M. \& Hoffman, H.S. (1962). A progression for generating variable-interval schedules. Journal of the Experimental Analysis of Behavior, $\underline{5}, 529-530$. Gleeson, S. (1991). Response acquisition. In I. Iverson \& K.A. Lattal (Eds.), Experimental Analysis of Behavior: Part I (pp. 63-86). Amsterdam: Elsevier Science Publishers B.V. Gollub, L. (1977). Conditioned reinforcement: Schedule effects. In W.K. Honig \& J.E.R. Staddon (Eds.), Handbook of Operant Behavior (pp. 288-312). Englewood Cliffs, NJ: Prentice Hall. Kelleher, R.T., Riddle, W.C. \& Cook, L. (1962). Observing responses in pigeons. Journal of the Experimental Analysis of Behavior, $\underline{5}, 3-13$.

Kendall, S.B. \& Gibson, D.A. (1965). Effects of discriminative stimulus removal on observing behavior. The Psychological $\underline{\text { Record, }} \underline{15}, 545-551$.

Lattal, K.A. \& Gleeson, S. (1990). Response acquisition with delayed reinforcement. Journal of Experimental Psychology: Animal Behavior Processes, $16,27-39$. Lattal, K.A. \& Metzger, B. (1994). Response acquisition by Siamese fighting fish (Betta splendens) with delayed visual 
reinforcement. Journal of the Experimental Analysis of

Behavior, $61,35-44$.

Lattal, K.A. \& Williams, A.M. (1996). Body weight and response acquisition with delayed reinforcement. Journal of the Experimental Analysis of Behavior, 67, 131-143.

Patterson, D.D. \& Winokur, S. (1973). Autoshaping pigeons' keypecking with a conditioned reinforcer. Bulletin of the Psychonomic Society, 1, 247-249.

Rashotte, M.E. (1981). Second-order conditioning: Contributions to the research and theory of Pavlovian reinforcement by conditioned stimuli. In C.M. Locurto, H.S. Terrace \& J. Gibbon (Eds.), Autoshaping and Conditioning Theory (pp. 139180). New York: Academic Press.

Rashotte, M.E., Griffin, R.W. \& Sisk, C.L. (1977). Second-order conditioning of the pigeon's keypeck. Animal Learning and Behavior, $\underline{5}, 25-38$.

Royalty, P., Williams, B.A. \& Fantino, E. (1987). Effects of delayed reinforcement in chain schedules. Journal of the Experimental Analysis of Behavior, 47, 41-56.

Schwartz, B. \& Gamzu, E. (1977). Pavlovian control of operant behavior: An analysis of autoshaping and its implications for operant conditioning. In W.K. Honig \& J.R.E. Staddon (Eds.), Handbook of Operant Behavior (pp. 53-97). Englewood Cliffs, NJ: Prentice Hall. 
Sidman, M. (1960). Tactics of Scientific Research. New York:

Basic Books.

Skinner, B.F. (1953). Science and Human Behavior. New York: Macmillan.

Wilkenfield, J., Nickel, M., Blakely, E. \& Poling, A. (1992). Acquisition of lever-press responding in rats with delayed reinforcement: A comparison of three procedures. Journal of the Experimental Analysis of Behavior, 58, 431-443.

Williams, A.M. (1996). Response acquisition with delayed reinforcement in the presence of an irrelevant operandum. Unpublished doctoral dissertation, West Virginia University . Williams, B.A. (1994). Conditioned reinforcement: Experimental and theoretical issues. The Behavior Analyst, 17, 261-285. Wyckoff, L.B. (1952). The role of observing responses in discrimination learning: Part I. Psychological Review, 59, $431-442$

Zimmerman, D.W. (1957). Durable secondary reinforcement: Method and theory. Psychological Review, $\underline{6}, 373-383$. 


\section{Appendix}

Med-PC Program To Control Experimental Events

$\backslash$ Multiple/mixed VI60 ExT schedule

$\checkmark$ With or without observing contingency

$\backslash 10 s$ resetting delay, $S+$ produced only

$\backslash$

$\backslash a=$ which component

$\backslash \mathrm{b}=$ component counter

$\backslash \mathrm{C}=$ component list

$\backslash d=$ counts pecks during extinction

$\backslash e=$ counts pecks during $v i$

$\backslash$ f=extinction component timer [f(0)] extinction component duration [f(1)]

$\backslash \mathrm{g}=\mathrm{vi}$ component timer

$\backslash \mathrm{h}=$ session time in minutes (display)

$\backslash i=v i$ interval list

$\backslash j=v i$ interval countdown

$\backslash \mathrm{k}=$ resolution increment

$\backslash l=e x t i n c t i o n$ component counter

$\backslash \mathrm{m}=\mathrm{vi}$ component counter

$\backslash \mathrm{n}=$ delay timer

$\backslash \mathrm{o}=$ counts $\mathrm{vi}$ observing responses

$\backslash p=$ counts ext observing responses

$\backslash q=S+$ duration

$\backslash r=i n d e x$ St on/off

$\backslash \mathrm{s}=\mathrm{Z}$ array element

$\backslash t=r e a l t i m e$ timer

$\backslash u=i n d e x$ which component just ended

$\backslash \mathrm{v}=$ index mult or $\operatorname{mix}[\mathrm{v}(0)]$; obs/no obs [v(1)]; treadle counter $[(\mathrm{v}(2)]$

lcounter for conditioned reinforcers presented [v(3)];

1 extinction timer $[\mathrm{V}(5)]$; VI timer $[\mathrm{V}(6)]$; rates [v $(7-12)]$

$\backslash \mathrm{w}=$ index which component is in operation

$\backslash x=$ number of reinforcers delivered

$\backslash y=i n d e x$ whether $v i$ is timed out

$\backslash \mathrm{z}=$ event markers in "real time":

.1 = primary reinf delivery

$.15=$ treadle onset

.2 = treadle release

$.24=$ treadle onset (no obs)

$.25=$ treadle offset (no obs)

$.3=\mathrm{s}+$ onset

$.35=s+$ offset

.4 = Extinction onset

$.5=$ VI onset 
$\backslash 0=\mathrm{EXT} \quad 1=\mathrm{VI}$

$\backslash$ random sequence of components

list $\mathrm{C}=1,0,0,1,0,0,1,1,0,1,1,0,1,0,0,1,0,0,1,0,1,1,0,0,1,0,0,1,0$, $1,0,0,1,0,1,1,0,0,1,0,0,1,1,0,0,1,0,1,1,0,1,0,1,1,0,1,1,0,1,1$

IVI interval values

list $\mathrm{I}=$

$1.526 ", 4.685 ", 8.020 ", 11.551 ", 15.304 ", 19.307 ", 23.596 ", 28.216 "$, $33.222 ", 38.684 ", 44.694 ", 51.375 ", 58.894 ", 67.495 ", 77.542 ", 89.623 "$, $104.784 ", 125.171 ", 156.566 ", 239.744 "$

$\wedge \mathrm{hop}=1$

$\wedge$ rkey $=3$

$\wedge \mathrm{gkey}=7$

${ }^{\wedge} \mathrm{wkey}=6$

$\wedge$ house $=4$

$\operatorname{dim} z=5000$

$\operatorname{dim} \mathrm{f}=2$

$\operatorname{dim} \mathrm{v}=12$

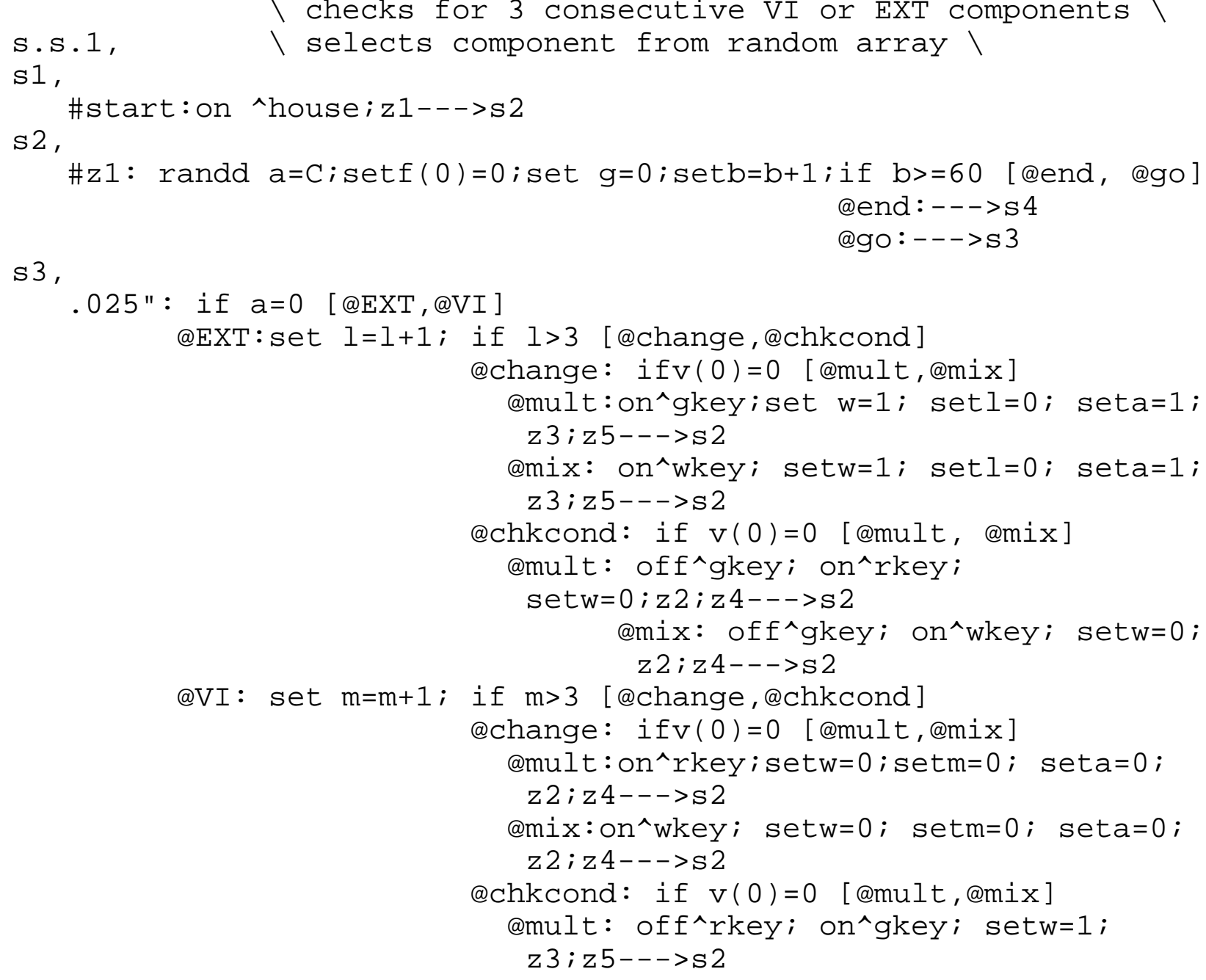




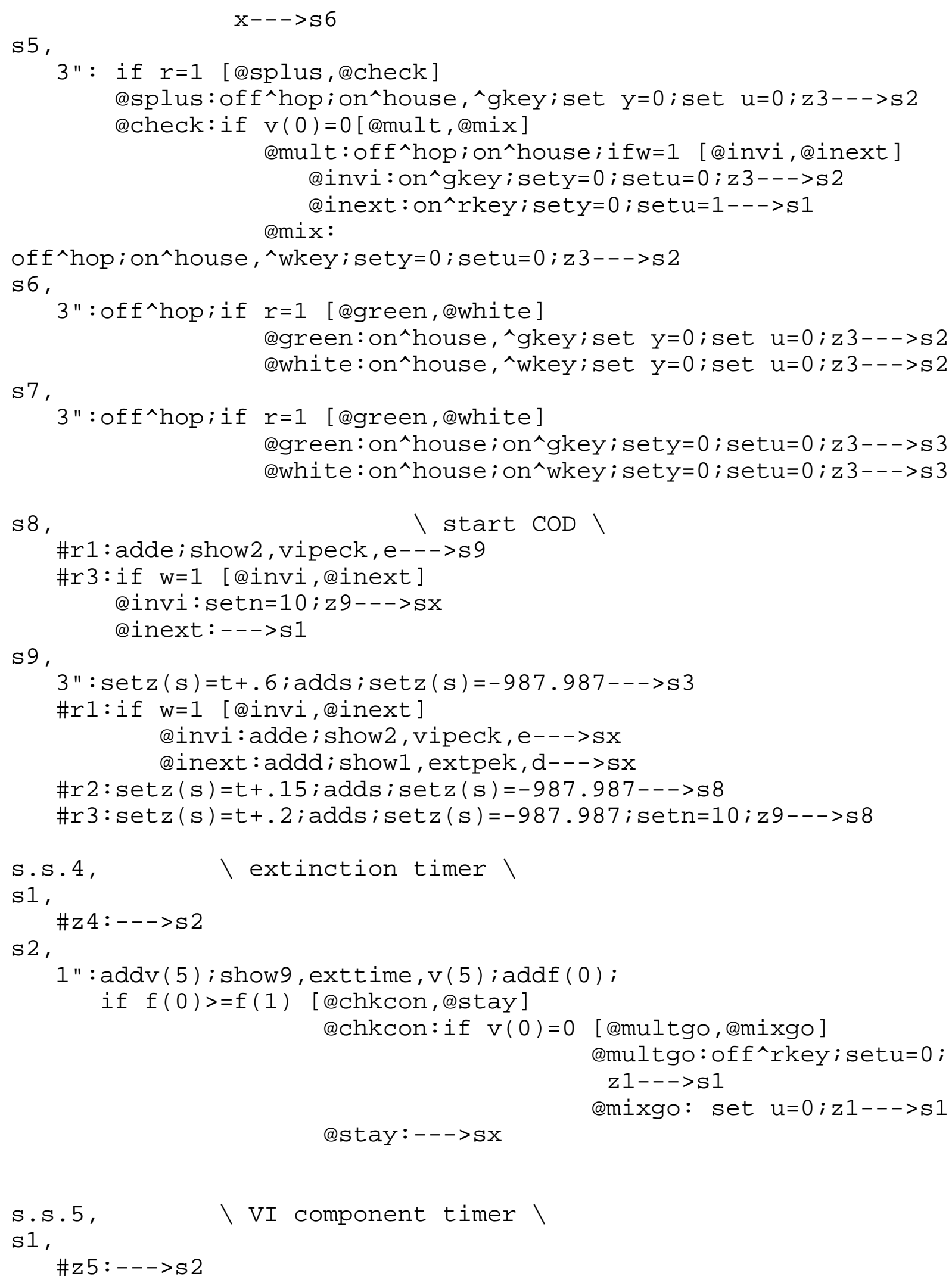




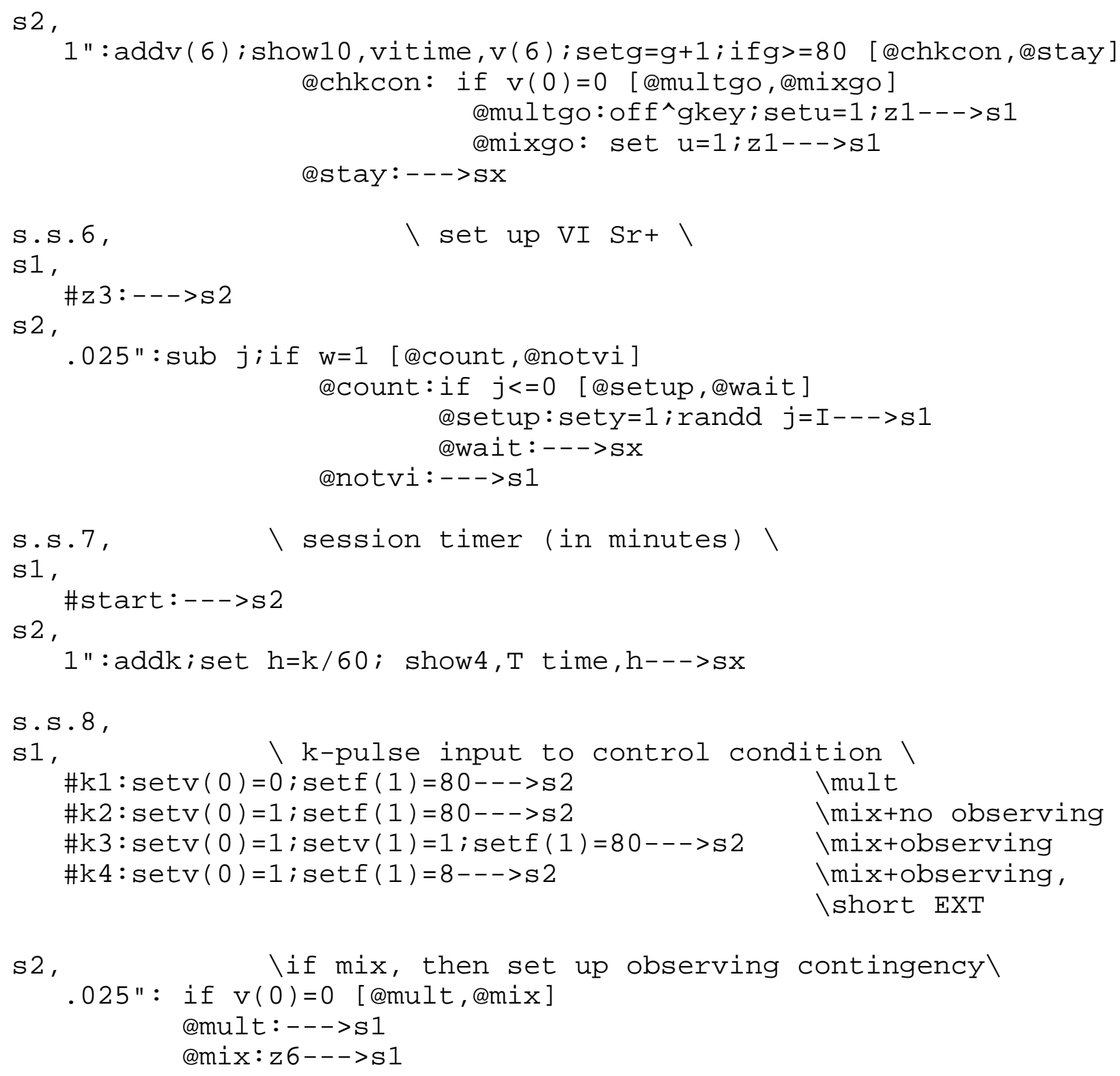




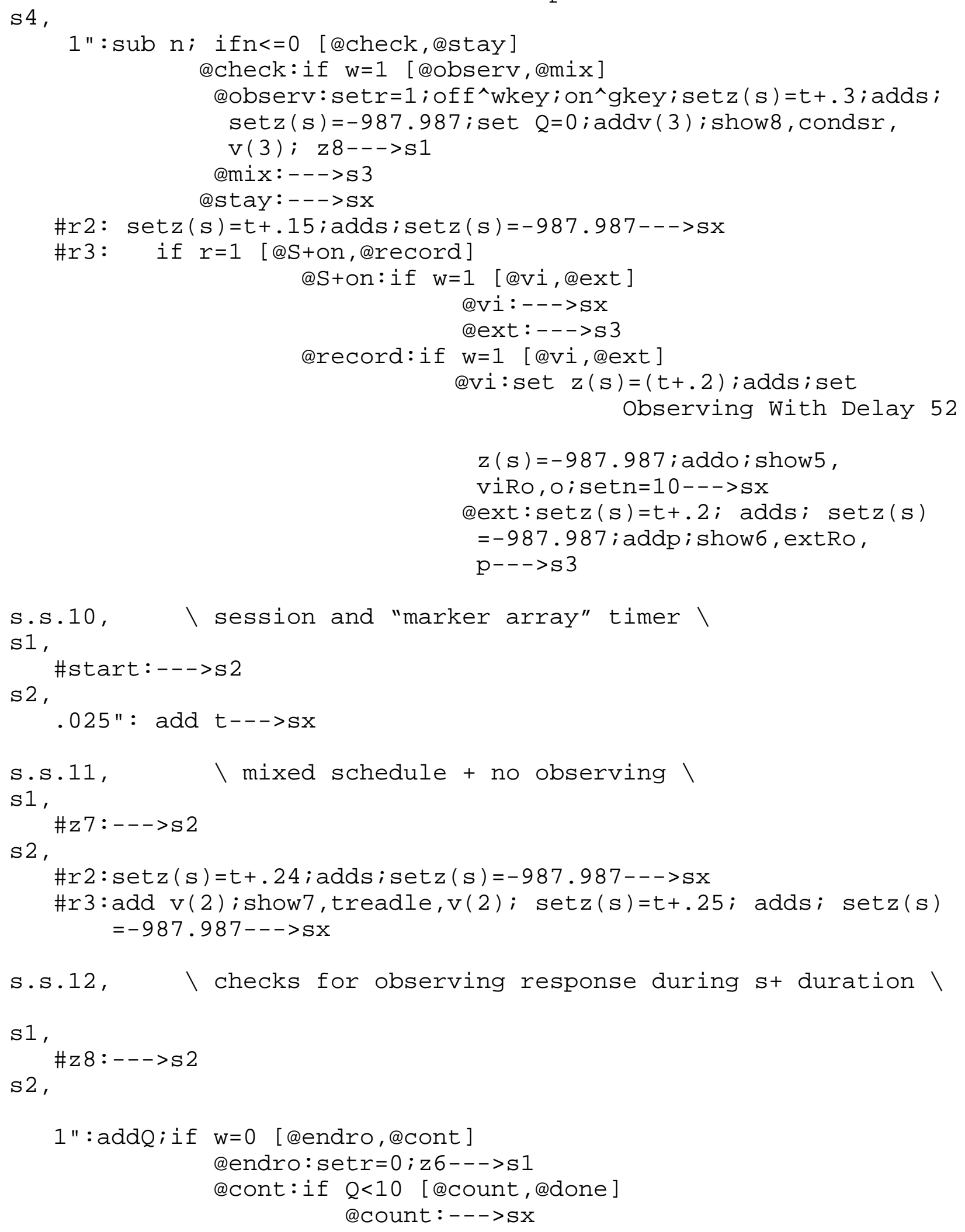


@done: setr $=0 ;$ off^gkey; on^wkey; $\operatorname{setz}(\mathrm{s})=$ $t+.35 ;$ adds; $\operatorname{set} z(s)=-987.987 ; z 6--->s 1$ $\# r 2: \operatorname{set} z(s)=t+.15 ; \operatorname{adds} ; \operatorname{set} z(s)=-987.987--->s x$

$\# r 3$ : addo; show5, viro, o; setz $(s)=t+.2 ;$ adds; setz $(s)=-987.987$; set $\mathrm{n}=10 ; \mathrm{z} 9--->\mathrm{s} \mathrm{x}$ 
Abstract

Six pigeons were trained to key peck for 3-s access to mixed grain on a multiple variable-interval 60-s extinction schedule. The schedule then was changed to a mixed variable-interval 60-s extinction schedule. Simultaneously, a treadle was introduced into the chamber. For 3 pigeons, the stimulus correlated previously with the variable-interval schedule could be produced by treadle pressing (i.e., an observing response) on a tandem fixed-ratio 1 differential-reinforcement-of-other-behavior 10-s schedule. For the other 3 pigeons, no contingency was implemented for treadle pressing. Treadle pressing was established equally in the presence and absence of the observing contingency. The results did not extend previous findings on response acquisition with delayed reinforcement to delayed conditioned reinforcement. Several aspects of the observing procedure are discussed, including the rate of food reinforcement, delays to food, and schedule preference. 


\author{
Acquisition of Observing Responses \\ With Delayed Conditioned Reinforcement \\ By \\ Gregory A. Lieving \\ A THESIS \\ Submitted to \\ West Virginia University \\ in partial fulfillment of the requirements \\ for the degree of Master of Arts \\ APPROVAL OF EXAMINING COMMITTEE
}

Robert P. Hawkins, Ph.D.

David W. Schaal, Ph.D.

Date

Kennon A. Lattal, Ph.D., Chair 